\title{
ALTERNATIVAS AL PODER CORPORATIVO: BOSQUEJO DE UN MARCO DE REFERENCIA PARA LA DISPUTA DEL CONFLICTO CAPITAL-VIDA
}

\author{
Gonzalo Fernández Ortiz de Zárate \\ Coordinador de Paz con Dignidad-Euskadi e investigador del Observatorio de Multinacionales \\ en América Latina (OMAL)
}

DOI: $10.1387 /$ lan-harremanak.16090

\section{ABSTRACT}

El artículo pretende ser un insumo a los debates teóricos y políticos en los que se enmarcan las alternativas que enfrentan el poder económico, cultural, politico y jurídico que hoy en día acumulan las empresas transnacionales, agentes hegemónicos en el modelo vigente de sociedad global. Este modelo es la manifestación actual del proyecto civilizatorio de la modernidad capitalista, cuyos valores y parámetros fundamentales están poniendo en riesgo la propia reproducción de la vida, agudizando el conflicto entre esta y el capital. Debido a ello, urge generar un relato alternativo al hegemónico que incida en las grandes mayorías sociales y que permita impulsar estrategias de transición desde parámetros antagónicos a los vigentes. En este sentido y a modo de conclusión, se propone un bosquejo de marco de referencia construido desde la crítica a la epistemología capitalista y a partir de la apuesta por la articulación de diversos enfoques emancipadores e inclusivos, nacidos directamente de los aprendizajes que nos ofrecen las múltiples prácticas de resistencia contrahegemónica.

Palabras clave: crisis, empresas transnacionales, marco de referencia, alternativas, transición. 
The article sets out to contribute to the theoretical and political debates that frame the alternatives to the economic, cultural, political and legal power built up today by transnational corporations, the hegemonic players in the current model of global society. This model is today's manifestation of the civilising project of capitalist modernism, whose fundamental values and parameters are placing at risk the reproduction of life itself, exacerbating the conflict between life and capital. It is therefore urgent to generate an alternative to the hegemonic narrative that influences the vast majority of societies, an alternative that makes it possible to pursue strategies for transition on the basis of parameters contrary to those that currently predominate. In this respect, by way of a conclusion, a rough frame of reference is proposed, built on the basis of a criticism of capitalist epistemology and a commitment to articulating diverse emancipating, inclusive approaches, the direct fruit of the lessons to be gleaned from the multiple practices of anti-hegemonic resistance.

Keywords: crisis, transnational corporations, frame of reference, alternatives, transition.

Artikuluak enpresa transnazionalek eta beste eragile nagusi batzuek metatzen duten botere ekonomiko, kultural, politiko eta juridikoaren aurka kokatzen diren eztabaida politiko eta teorikoentzat ekarpenak ekarri nabi ditu. Eredu hau modernitate kapitalistaren zibilizazio-proiektuaren adierazpena da, bere balore eta parametroak arriskuan ipintzen ari dira bizitzaren ugalketa, hauxe eta kapitalaren arteko gatazka larriagotuz. Horregatik, gizarte-gehiengoan eragina duen eta gaurko parametroen kontra oinarritutako trantsizio estrategiak bultzatzen duen ordezko ildoa sortzea premiazkoa da. Zentzu honetan eta konklusio moduan, hona hemen jositako erreferentzia-marko zirriborroa, epistemologia kapitalistaren ikuspuntu kritikotik eta ikuspegi emantzipatzaile eta inklusibo aldeko apustu batetik, erresistentzia kontrahegemoniko praktika hainbatetan topatzen ditugun ikastetan jaiota.

Hitz gakoak: krisia, enpresa transnazionalak, erreferentzia markoa, aukerak, trantsizio. 


\section{Conflicto capital-vida como eje de la actual crisis civilizatoria}

Existe en la actualidad un amplio consenso académico y social sobre la gravedad y el carácter sistémico de la crisis que estamos atravesando. En este sentido, se destaca no solo lo complejo de su análisis — debido a las múltiples variables que interactúan y a la interdependencia global de los diferentes territorios- sino también de su superación, en un momento en el que tanto las respuestas como las preguntas parecen haber cambiado (Dubois, 2014; Sousa, 2006).

Así, los parámetros hegemónicos del modelo de sociedad global están mostrando sus carencias a la hora de enfrentar nuevos problemas como el cambio climático, la crisis energética o la adecuación de los conceptos políticos de ciudadanía y soberanía a la actual fase de globalización neoliberal — por poner solo algunos ejemplos-, en un contexto fluctuante, dinámico y sin precedentes en la historia de la humanidad. De esta manera, el consenso sobre la crisis incorpora un quinto elemento a los cuatro ya señalados (gravedad, carácter sistémico, dificultad de análisis y complejidad de su superación), que no es sino la incertidumbre. Esta hace referencia no solo a las herramientas políticas para enfrentar nuestra actual coyuntura, sino también incluso a los propios objetivos que se han posicionado como prioritarios en nuestra sociedad global, crecientemente cuestionados (Dubois, 2016).

En todo caso, la crisis genera un consenso significativo pero básico, a partir del cual se desarrolla un gran número de diagnósticos y propuestas de muy diferente signo. Así, en este momento complejo e incierto donde los modelos y las verdades absolutas pierden vigencia, conviven múltiples relatos sobre la realidad que, a partir de enfoques, miradas, intereses y poderes disímiles y asimétricos, ofrecen respuestas muy diversas a las grandes preguntas derivadas del consenso antes señalado: cuál es la raíz sistémica de la crisis, qué variables intervienen en su gestación, y cuáles son por tanto las claves para enfrentarla. El resultado es un muy amplio abanico de interpretaciones teóricas y políticas, difíciles de categorizar y ordenar. No obstante, una posible variable que podría ayudarnos en este sentido es el grado de intensidad estructural tanto en el análisis de la crisis como en la profundidad de las transformaciones propuestas para superarla. 
Figura 1

Abordajes de la crisis

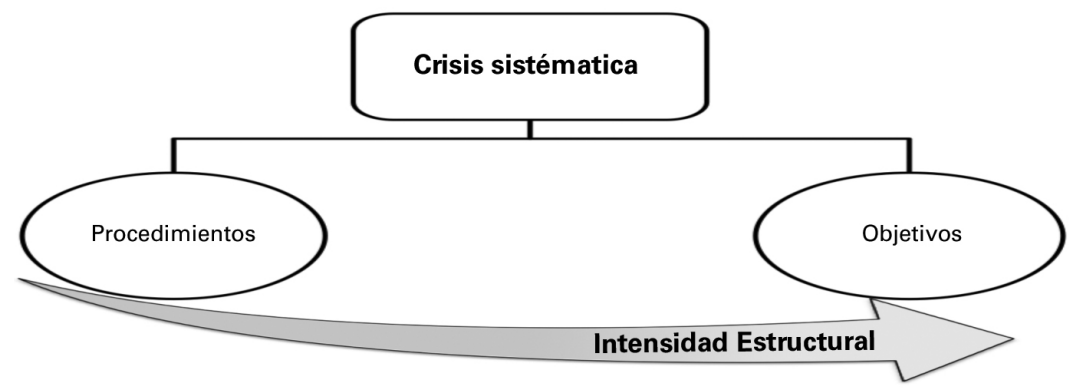

Fuente: Elaboración propia.

De esta manera, los diferentes enfoques se podrían clasificar en función del menor o mayor cuestionamiento de los objetivos e ideas-fuerza hegemónicos del modelo vigente de sociedad global (progreso, desarrollo, crecimiento, mercado, democracia liberal-representativa, etc.). Definiríamos así una línea de continuidad en la que partiríamos de un extremo de menor intensidad en el que no se cuestionan sino que se reafirman dichos parámetros sistémicos. Por tanto, el origen de la crisis y la necesidad de cambios estructurales no se sitúa en los objetivos, sino en la revisión de ciertos procedimientos que pudieran haber fallado -agentes, políticas o prácticas específicas-, y para los cuales se plantean diversas propuestas de superación. Estas se refieren fundamentalmente a determinadas transformaciones en el formato actual de gobernanza mundial, necesarias para enfrentar la creciente tensión entre globalización económica y democracia liberal-representativa, o lo que es lo mismo, entre poder económico y poder político ${ }^{1}$, pero sin cuestionar el papel central del crecimiento económico capitalista. A partir de este extremo inicial avanzaríamos en la intensidad del señalamiento de dichos procedimientos hasta llegar, en un salto cualitativo, al posicionamiento de ciertos objetivos y valores centrales del modelo vigente como génesis del problema. Finamente, y en el extremo de máxima intensidad estruc-

${ }^{1}$ Son múltiples las propuestas que se podrían incluir en esta categoría que, sin negar la complejidad de la crisis actual y sus múltiples manifestaciones, optan por no vincularlas con la hegemonía del crecimiento económico capitalista, centrándose así en la propuesta de nuevos procedimientos que complementen o limiten dicha hegemonía. Destacamos por ejemplo el conjunto de Informes de Desarrollo Humano del PNUD (http://www.undp.org/content/undp/es/home/librarypage/hdr. html) y del Banco Mundial (http://documentos.bancomundial.org/curated/es/docsearch/documenttype/563760), el informe DESA de Naciones Unidas (DESA, 2010), o el Informe Un nuevo Partenariado global: erradicar la pobreza y transformar las economías hacia el desarrollo sostenible, del Panel de Alto Nivel de Personas Eminentes en torno a la Agenda Global de Desarrollo Post-2015 (Naciones Unidas, 2013). 
tural de nuestra línea de análisis, posicionamos la crítica al conjunto de parámetros no solo sistémicos sino incluso civilizatorios, como centro del análisis de la crisis (Fernández, Piris y Ramiro, 2013).

Esta clasificación tentativa, que diferencia entre procedimientos y objetivos globales, nos permite relacionar y explicar — dentro del amplio abanico antes señalado - tres de las principales miradas sobre nuestra realidad vigente: la hegemónica, la unidimensional y la civilizatoria, de cuyo análisis comparativo extraeremos el punto de partida de nuestro bosquejo de marco de referencia.

En primer lugar la mirada hegemónica — defendida, impulsada y relatada por los principales organismos multilaterales, regionales y estatales, así como por los centros estratégicos de poder corporativo-, se sitúa en el extremo inicial de nuestra clasificación sobre la crisis, sin cuestionar por tanto los principales objetivos y parámetros sistémicos ni sus acepciones más extendidas. Al contrario, su centro de análisis se sitúa en aquellos procedimientos del modelo actual de gobernanza mundial que han impedido desarrollar el potencial de dichos objetivos, siendo necesarias por tanto reformas estructurales que favorezcan sendas seguras de crecimiento económico.

En este sentido se apela a la voluntad colectiva de todos los agentes públicos y privados para enfrentar los retos mundiales — sin compromisos vinculantespor un lado, mientras que por el otro se otorga prioridad estratégica a garantizar el comercio y la seguridad en las inversiones a través de una nueva fase de tratados globales y regionales como el TTP, TTIP, CETA y TISA² (Zabalo, 2014), que definitivamente eliminen toda traba política y jurídica al pleno despliegue de la lógica capitalista. Estos nuevos acuerdos se sumarían a los más de 3.000 actualmente en vigor, dentro de una estrategia que pretende desbrozar el camino a los negocios a costa incluso de limitar las capacidades de gobiernos, pueblos y comunidades (Hernández y Ramiro, 2015; Teitelbaum, 2010), erigiendo al poder corporativo como el actor económico y político clave, garante principal y en última instancia de las posibilidades de bienestar colectivo.

La segunda interpretación que destacamos sobre la crisis - y que hemos definido como mirada unidimensional - se sitúa ya dentro de la categoría de cuestionamiento de los objetivos y valores hegemónicos. De esta manera, el énfasis exclusivo en los procedimientos como génesis de nuestra realidad actual se interpreta como un ejercicio de "miopía» que no sitúa el foco de atención en las causas sino en las consecuencias, por lo que sus propuestas de superación no solo no tienen el impacto esperado sino que incluso ahondan el problema. En este sentido, se consideran un compendio de iniciativas que oscilarían entre el vo-

\footnotetext{
${ }^{2}$ Respectivamente, y por sus siglas en inglés: Tratado Trans-Pacífico, Partenariado Trasatlántico de Comercio e Inversión, Acuerdo de Comercio entre Canadá y Europa, y Acuerdo de Comercio en Servicios.
} 
luntarismo infundado, la salida tecnocrática a un problema político, o la pretensión de lo que Frank Hinkelammert ha definido como "radicalizar el presente» (Sousa, 2006), esto es, insistir en una huida hacia adelante que fortalece aquello que precisamente es razón del momento de turbulencia actual.

Frente a ello, este enfoque unidimensional sí plantea el papel fundamental de una de las variables estructurales como génesis de la misma (sistema financiero, capitalismo, sistema político, cambio climático, agotamiento energético, etc.). No obstante, el resto de variables explicativas antes citadas y que también inciden en la crisis o bien se ningunean, o bien se incorporan al análisis desde una relación de dependencia y subordinación respecto a la considerada principal. En este sentido, esta dimensión referencial - fuera la que fuera- impone sus parámetros fundamentales en las estrategias de superación de la crisis (agenda, sujeto, marcos culturales), quedando las del resto de variables invisibilizadas y/o supeditadas a estas.

En esta categoría, y dentro de las diferentes interpretaciones unidimensionales de la crisis, ocupa un papel relevante la visión que sitúa la raíz única del problema en el capitalismo como sistema socioeconómico global. Desde este enfoque, el principal punto de análisis de la crisis se centraría en la creciente incapacidad del sistema económico para autorreproducirse, dadas sus propias dinámicas identitarias $\mathrm{y}$, particularmente, la dificultad de absorción del ingente excedente generado en la fase actual de desregulación financiera (Harvey, 2012). La realidad se mira así de manera exclusiva desde esta dimensión económica - por supuesto que imprescindible-, pero sin interseccionar esta con otras variables sociales, políticas, culturales, ecológicas, etc.

Finalmente, la tercera interpretación de la crisis como fenómeno civilizatorio sí emprende este intento holístico de aprehensión de las múltiples dimensiones que operan en su génesis. El concepto de crisis civilizatoria (Acosta, 2010; Echeverría, 2010; Ceceña, 2008; Fernández Durán y González, 2014; Fernández, Piris, Ramiro, 2013; León M., 2014; Naredo, 2006; Orozco, 2014; Vega, 2009; Valdés, 2009; Wilkinson, 2009) comparte con la mirada unidimensional su crítica al enfoque procedimental, pero se diferencia de esta al plantear que no son solo ciertas estructuras o dimensiones sistémicas analizadas de manera aislada las causantes únicas de la situación actual de crisis profunda. Al contrario, sería la articulación necesaria de múltiples dimensiones la que, respondiendo a una serie de valores y metas civilizatorias determinadas, han construido históricamente estructuras, sujetos, políticas y dinámicas de todo tipo que nos han conducido al atolladero histórico actual (Bartra, 2013).

De esta manera, las raíces de la crisis se sitúan en la existencia de una serie de parámetros que, a pesar de su mutación histórica y adaptación al contexto específico, definen a nuestra civilización en función de una serie de principios organizadores de la vida colectiva, que reconocen y adjudican valor a ciertos 
aspectos de la realidad, mientras que desconocen o desvalorizan otros (Wilkinson, 2009). En la actualidad, nuestro modelo de sociedad global se enmarca en el proyecto civilizatorio que denominamos como modernidad capitalista. Este, desde hace más de tres siglos y a partir de una matriz que se exportó de Europa al mundo (Giddens, 1990), posiciona el progreso, el individualismo, la ciencia como saber único, la dominación de la naturaleza por el ser humano, la acumulación capitalista y la democracia liberal-representativa como valores fundamentales, resumidos en el mantra civilizatorio de bienestar igual a progreso, que es igual desarrollo, que a su vez es igual a crecimiento económico capitalista (Fernández, 2014).

De esta manera el proyecto de la modernidad capitalista ${ }^{3}$ - que se entiende como la confluencia asimétrica del universo filosófico de la modernidad y su sustrato ilustrado, por un lado, con el capitalismo como propuesta hegemónica y universalizable en lo económico, por el otro- ha encumbrado los valores antes citados como fuertes - fundamentalmente derivados de la lógica capitalista-, mientras que mantiene algunas de las señas de identidad ilustradas como valores débiles del modelo civilizatorio (ciudadanía, soberanía, igualdad, libertad), supeditados y redefinidos en función de los primeros.

Se trata en definitiva de una civilización que acentúa su carácter productivo y consumidor; que resalta el papel de la naturaleza como simple proveedora de bienes; que prima el mercado por encima de toda actividad social; que establece el lucro como motivador principal de la acción de las personas (Wilkinson, 2009), y que lleva en su origen la huella indeleble de la desigualdad, la ingobernabilidad, la insostenibilidad y la violencia. En este sentido, la misma gestación de la modernidad capitalista parte de un proceso previo, fundacional y necesario de acumulación originaria —que sentó las bases para su eclosión posterior durante la Revolución Industrial — que se sustenta sobre la conversión violenta de las clases subalternas en proletariado a través del cercamiento, la privatización y la mercantilización; sobre la instauración de un nuevo orden patriarcal que, entre otras transformaciones, define una nueva división sexual del trabajo que supedita el rol de las mujeres a la reproducción, y que amputa y persigue su auto-

3 La modernidad capitalista se entiende como un proceso específico de confluencia del proyecto modernizador con el sistema capitalista. De esta manera el artículo se centra en la crítica a este concepto específico, sin entrar en el intenso debate entre modernidad y posmodernidad, entre si es posible o no otro tipo de modernidad de mayor carácter y voluntad emancipadora o no. Para dichos debates nos referimos entre otros al artículo de Ana Esther Ceceńa en este sentido (Ceceña, 2014). En todo caso, afirmamos como Boaventura de Sousa Santos que existe un mayor punto de encuentro entre la modernidad crítica y la posmodernidad de oposición — que plantea una revisión integral del sistema sin renunciar a referentes universales, aunque no basados en los valores clásicos modernosque entre esta última y la posmodernidad de celebración — que pudiera caer en un relativismo que únicamente celebra la diversidad y la diferencia, sin pretensiones de incidir sobre nuestras realidades- (Sousa, 2006). 
nomía; y sobre la colonización a sangre y fuego de multitud de países y pueblos en el Sur Global (Federici, 2014).

Y son precisamente estas prácticas de desigualdad, ingobernabilidad, insostenibilidad y violencia intrínsecas al proyecto modernizador las que, en la fase actual de globalización neoliberal, se han ahondado y desbocado, en una lógica de evolución natural de los valores fuertes del proyecto civilizatorio. De esta manera el énfasis en el progreso individual, en la primacía del lucro y de la ganancia como premisa de bienestar, así como la de democracia liberal-representativa como forma de organización política, han conducido a la modernidad capitalista a mostrar su verdadera identidad, más allá del relato teórico, a partir de un Sistema de Dominación Múltiple -SDM- (Valdés, 2009), que afecta a las grandes mayorías sociales y al conjunto del planeta.

Figura 2

Sistema de Dominación Múltiple

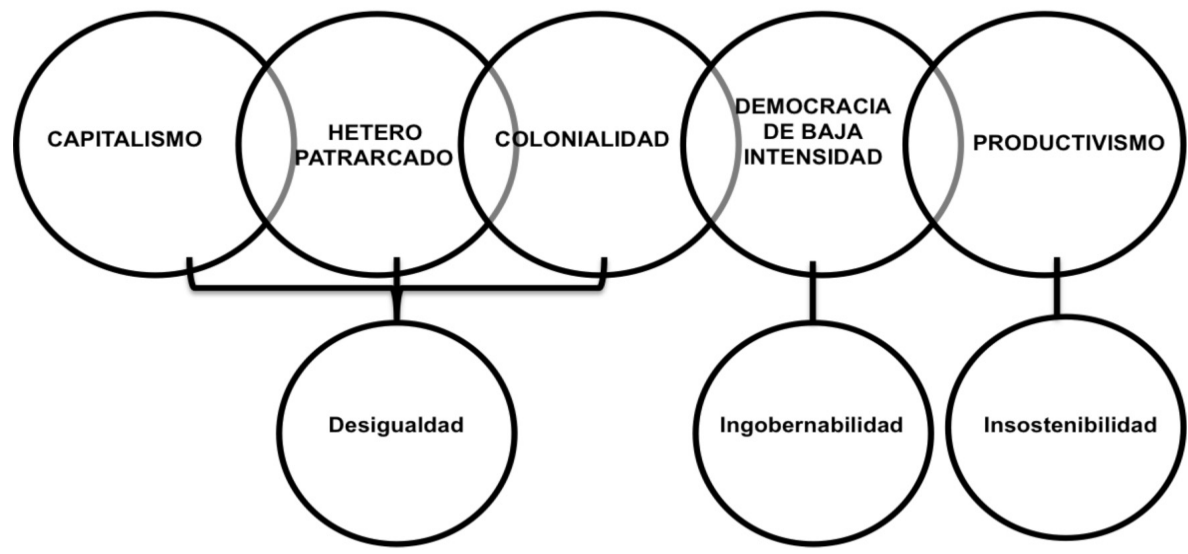

Fuente: Elaboración propia.

En este sentido, la modernidad capitalista/sistema de dominación múltiple articula en una misma lógica civilizatoria diversas dimensiones que se necesitan mutuamente y que acrecientan y justifican las desigualdades en base a la clase (capitalismo), en base al sexo y al género (heteropatriarcado) y en base a la raza/ etnia (colonialidad). Esta matriz de desigualdad estructural se constituye sobre un marco político en el que la participación popular se devalúa, privatizada y alejada de los ámbitos clásicos de ejercicio de la soberanía (democracia de baja intensidad). Como resultado de ello, esta democracia donde prima y destaca el poder corporativo sobre el político sitúa el crecimiento económico y la ganancia por encima de la sostenibilidad, llegando de esta manera y por primera vez en la 
historia de la humanidad a superar los límites físicos del planeta, poniéndolo en riesgo (productivismo) ${ }^{4}$. Por lo tanto, capitalismo, heteropatriarcado, colonialidad, democracia de baja intensidad y productivismo son parte necesaria e indivisible — no accidentes ni elementos ajenos - de un SDM que muestra la faceta más cruda del proyecto civilizatorio y que se sitúa en la génesis de la crisis actual.

Una crisis extremadamente grave que nos obliga a una revisión integral de dicho modelo civilizatorio, ya que este no es solamente incapaz de generar mayores cotas de bienestar, o de al menos garantizar su autosostenibilidad futura. Además, se plantea como plausible la posibilidad de que la modernidad capitalista pueda poner en riesgo la propia capacidad de la vida para reproducirse en el planeta (Bermejo 2010; Herrero y González, 2011). En este sentido, y más allá del debate ético y político sobre cuál es el nivel asumible de desigualdades y pobreza, la crisis climática (PNUD, 2008; Banco Mundial, 2010) y energética (Fernández Durán y González, 2014) muestran a las claras la imposibilidad de continuar en la senda hegemónica, ya que las premisas sobre las que esta se ha sustentado (sistema ecológico abierto y acceso infinito a energía y materiales) no son ciertas. Esto tiene ya graves consecuencias en el presente, que además pudieran ser funestas en las próximas décadas si no se producen transformaciones profundas. De esta manera, el centro del debate teórico y político no lo debería ocupar el hecho de si se producirá o no el cambio, sino más bien qué cambio se producirá, quién lo dirigirá y hacia qué horizonte nos dirige (Fernández Durán y González, 2014; Orozco, 2014).

En definitiva, y en nuestra opinión, esta interpretación civilizatoria de la crisis es la que ofrece un relato más coherente y de conjunto sobre las múltiples variables que interaccionan en la compleja realidad actual, superando miradas unidimensionales que, pese a su relevancia, no ofrecen una mirada histórica, sistémica y política de conjunto. En este sentido, el concepto de crisis civilizatoria destaca una serie de parámetros que se mantienen vigentes a lo largo de los últimos siglos y caracterizan al modelo hegemónico de sociedad global lo que nos permite, en primer lugar, realizar una mirada de largo alcance sobre las causas del fenómeno. En segundo lugar, nos alerta de la gravedad de la situación que atravesamos, y nos señala dónde se encuentra la génesis de la misma, concretamente en una serie de valores que generan un sistema de dominación múltiple. Por último, y en tercer lugar, nos urge en consecuencia a actuar, a confrontar, a construir y posicionar alternativas que, desde una perspectiva inclusiva, se enfrenten al proyecto de la modernidad capitalista.

\footnotetext{
${ }^{4}$ Para ver la lógica de necesidad y articulación de estas diferentes dimensiones, ver Fernández, Piris y Ramiro (2013: 34-44).
} 
Por eso mismo la crisis civilizatoria es el primero de los elementos de nuestro marco de referencia. Y precisamente vinculado al mismo surge el segundo de los conceptos clave: el conflicto capital-vida (Fernández 2015; Orozco 2014). Este se deriva de manera natural de lo previamente señalado sobre la necesidad y urgencia por confrontar al modelo hegemónico desde el posicionamiento de objetivos y valores alternativos. De esta manera el capital, como metáfora inclusiva de la modernidad capitalista y como valor sistémico principal, es incompatible con el bienestar general y con la reproducción de la vida en última instancia, por lo que la disputa entre el capital y la vida se convierte en la idea-fuerza estratégica de todo esfuerzo de emancipación ${ }^{5}$.

No obstante, no podemos entender este conflicto capital-vida desde una perspectiva maniquea, en la que se enfrentan fuerzas perfectamente definidas y delimitadas, o en el que confrontan supuestas abstracciones (capitales), por un lado, contra todos los seres humanos y la naturaleza, por el otro. Al contrario, tres son las claves que deberíamos tener en cuenta para analizar esta idea-fuerza. En primer lugar, no hay un solo capital, ya que en este conviven estrategias diferentes que responden a contextos, identidades y propuestas diversas, aunque compartan en muchas ocasiones ciertos parámetros comunes. En este sentido, el conflicto capital-vida hace referencia a quienes propugnan, impulsan, defienden y se benefician del proyecto de la modernidad capitalista. En segundo lugar, se parte de la premisa de que dicho proyecto civilizatorio tiene un carácter político, y por tanto no es una abstracción o una entelequia, sino que está materializado en poderes, propuestas, agentes y personas concretas, cuerpos de "carne y hueso" que pugnan y disputan espacios a otros proyectos de muy diferente signo. En tercer lugar, la vida es un fenómeno complejo y diverso, por lo que el conflicto capital-vida rompe con la falsa dicotomía entre humanidad y naturaleza, a la vez que nos obliga a analizar la realidad — y a tratar de transformarla — desde las diferentes y asimétricas situaciones y posiciones que las personas, grupos, comunidades, pueblos y movimientos ocupamos en función de nuestra clase, género, etnia/raza, identidad sexual, etc.

Esto por supuesto complejiza los análisis y las propuestas de transformación. En este sentido, exige una disección profunda de los capitales y de los proyectos que hay detrás de ellos para romper inercias civilizatorias y la legitimidad que hoy en día todavía atesoran. A su vez exige una articulación de agendas y sujetos múltiples y diversos que asuman el conflicto capital-vida como prioritario, y que enfrenten de manera integral al SDM —no solo a algunas de sus dimensio-

5 No se trata de rescatar por tanto al capital y a sus lógicas sistémicas como la única dimensión de interpretación y de actuación política ante la crisis. Más bien el conflicto capital-vida pretende ejemplificar la incompatibilidad entre la vida y una modernidad capitalista donde el crecimiento económico capitalista juega un papel catalizador, por lo que es un elemento necesario del mismo, aunque no suficiente. 
nes-, posicionando imaginarios, objetivos, agentes y prácticas fundadas en valores alternativos a los hegemónicos.

En definitiva, el análisis de la crisis como fenómeno civilizatorio y el conflicto capital-vida como idea-fuerza teórica y política son parte del diagnóstico del presente trabajo sobre la realidad global, y se convierten en los dos primeros elementos de nuestra propuesta de marco de referencia para las alternativas a las empresas transnacionales. Estas juegan un papel estratégico y prioritario en dicho conflicto al posicionar su poder económico, cultural, político y jurídico, en términos generales, al servicio y en defensa de los valores hegemónicos.

\section{El poder corporativo en el conflicto capital-vida}

Las empresas transnacionales son corporaciones constituidas por una sociedad matriz en conformidad con la legislación de un país determinado, que se implanta en otros países mediante inversiones directas — sin crear sociedades locales o mediante filiales que se constituyen como sociedades según la legislación del país huésped-, y que mantiene una estrategia común dirigida por un centro corporativo que toma las principales decisiones relacionadas con la producción, la localización de plantas, la comercialización, el financiamiento, etc. Dentro de esta caracterización general son múltiples las tipologías vinculadas, que van desde grupos del mismo sector de actividad, hasta los holdings que dirigen empresas desde un capital accionarial compartido, pasando por los conglomerados en los que las actividades son múltiples y variadas (Hernández, González y Ramiro, 2012).

Estas grandes empresas se han convertido hoy en día en uno de los principales agentes del modelo vigente de sociedad global, posición a la que han llegado como respuesta a la evolución histórica y política de las claves identitarias de la modernidad capitalista. Así, la prevalencia de los valores hegemónicos y el desarrollo de ciertas capacidades tecnológicas vinculadas al transporte, la comunicación, la información, etc., propiciaron la conformación de estas grandes corporaciones, fruto de un proceso que se impulsa a finales del siglo XIX —a partir de la concentración generada por la fusión del capital industrial y financiero-, y que en última instancia se fortalece durante la fase de globalización neoliberal que se desarrolla desde los ańos 70 del siglo pasado hasta nuestros días.

En este sentido, la globalización neoliberal —etapa como decimos de acumulación exponencial del poder corporativo-, podría describirse como un proyecto político específico que trata de responder a la crisis a partir de una aún vigente contrarrevolución conservadora (Fontana, 2011). En este sentido, la agenda hegemónica de esta contrarrevolución, conocida como Consenso de 
Washington ${ }^{6}$ (mercantilización, desregulación, apertura de mercados, flexibilización, privatización) pretende, por un lado, la eliminación progresiva de toda traba al desarrollo de los parámetros identitarios de la modernidad capitalista a la vez que su adaptación, por el otro, a las nuevas posibilidades de organización económica mundial. En esta lógica, se destaca específicamente la necesidad de limitar el poder de la clase trabajadora y de las organizaciones sindicales, de disciplinar al Sur Global, así como de coartar las capacidades de los estados a la hora de impulsar políticas de manera autónoma ${ }^{7}$. El objetivo del proyecto se plantea, en última instancia, como la posibilidad de generar un nuevo modelo económico y político global en base a parámetros comunes que permitan ampliar las fronteras espaciales, sectoriales y políticas de los valores civilizatorios hegemónicos (Fernández, 2015).

Y es en el marco de implementación de este modelo en el que las empresas transnacionales se convierten en el agente fundamental de la modernidad capitalista y, por tanto, también del conflicto capital-vida. Con esta aseveración no queremos simplificar esta disputa, señalando a las grandes corporaciones como los bastiones únicos en defensa del proyecto civilizatorio. Como ya hemos señalado previamente - y como posteriormente veremos-, el análisis es mucho más complejo, ya que por un lado ni el fin de este tipo de empresa asegura la pérdida de hegemonía de los valores civilizatorios vigentes, ni por el otro cualquier agenda de confrontación con estas será válida para aglutinar al sujeto múltiple y diverso en defensa de la vida. No obstante, y partiendo de esta necesaria precisión, las empresas globales sí se pueden caracterizar en la actualidad no solo como las principales beneficiarias del proceso de globalización neoliberal, sino también como quienes lo impulsan y defienden de una manera más fehaciente, ya que su suerte está vinculada al mismo (Hernández y Ramiro, 2015). Así, ha habido modernidad capitalista sin grandes corporaciones, pero estas no pueden sobrevivir sin las claves identitarias de la modernidad capitalista, por lo que podemos afirmar que las empresas transna-

6 En esa misma lógica situamos al post-Consenso de Washington, que a partir de inicios del siglo xxi supera la consideración del estado como un agente que debe ser limitado al máximo en sus capacidades. No obstante, no supone un cambio de estrategia, ya que se recupera el rol de los estados pero desde su reconocimiento como actores necesarios para la implementación del mismo proyecto de la globalización neoliberal, supeditado siempre y en todo caso al poder corporativo.

7 Podemos analizar las similitudes en la concepción de la génesis y propuesta de transformación que se dio en los años 70 y la que se ofrece en la actualidad, dado como decimos a que ambas responden a los mismos parámetros civilizatorios hegemónicos. No obstante, el contexto es muy diferente, así como la gravedad de la situación, ya que en primer lugar el poder corporativo hoy en día está mucho más extendido — sobre todo en términos relativos respecto al poder político- Por otro lado y en segundo lugar, existe en la actualidad un riesgo sistémico mucho más grave derivado de la situación ecológica, debido a la crisis climática y al agotamiento de los recursos fósiles sobre los que se asienta el modelo actual, los cuales son prácticamente imposibles de sustituir en las condiciones actuales (Fernández Durán y González, 2014) 
cionales son agentes necesarios y estratégicos — aunque no suficientes - para afrontar el conflicto capital-vida.

Partiendo de esta premisa, es importante remarcar que las grandes corporaciones acumulan en la actualidad un poder sin precedentes en la historia, que trasciende lo económico para ampliarse hacia lo cultural, lo político y lo jurídico, dando lugar a un orden global que se va conformando a su medida (Teitelbaum, 2010). Analizaremos a continuación la articulación de este múltiple poder económico, cultural, político y jurídico, adelantando previamente cuatro de los rasgos definitorios de la hegemonía que hoy en día ostentan: en primer lugar, el control del centro neurálgico de la economía a través de sus mercados y cadenas globales; en segundo lugar, la primacía del relato que las vincula con el progreso y el éxito dentro del imaginario colectivo; en tercer lugar, la capacidad de redefinir a medida una democracia de baja intensidad, que supedita definitivamente el poder político al económico; por último, y en cuarto lugar, la implantación de una arquitectura de la impunidad en base al Derecho Corporativo Global, una lex mercatoria que se sitúa por encima de los derechos humanos y de la naturaleza, y que cierra el "círculo» de poder en favor de las grandes empresas desde el ámbito jurídico (Hernández y Ramiro, 2015; Teitelbaum, 2010).

Figura 3

Poder Corporativo

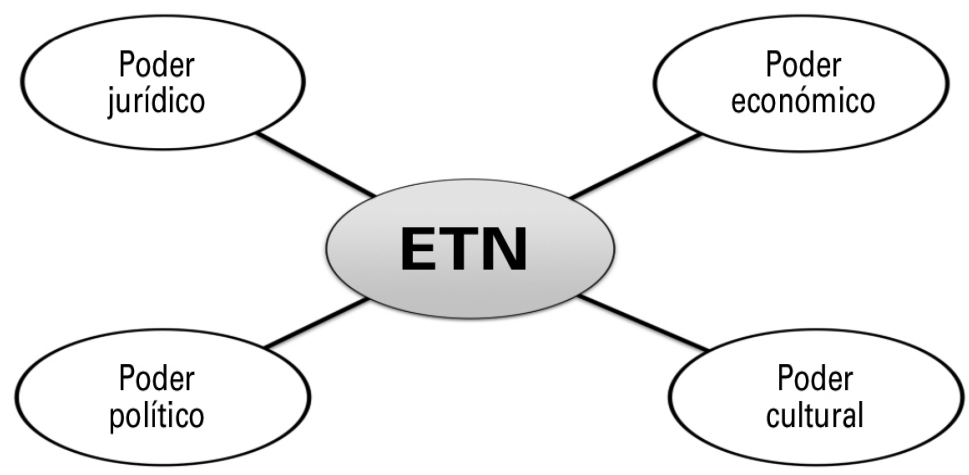

Fuente: Elaboración propia.

Comenzando con el multidimensional análisis del poder corporativo y centrándonos inicialmente en el ámbito económico, podemos destacar que las empresas transnacionales son los principales agentes de los mercados globales -y de las cadenas de producción, distribución, comercio, finanzas, tecnología y comunicación que operan en los mismos- que dan forma al nuevo modelo eco- 
nómico generado en las últimas décadas. Este, gracias a las innovaciones antes citadas en el ámbito del transporte, la información y la comunicación, ha posibilitado un marco global de actuación que ha ampliado los mercados capitalistas (espacial y sectorialmente), siendo las grandes corporaciones las que mantienen el control operativo de dichas cadenas y mercados. Este control se ejerce a través de la toma de decisiones estratégicas, de la fuerza de sus capacidades tecnológicas y financieras, así como de la organización del sistema productivo y de distribución a lo largo de toda la cadena de valor. De esta manera, tienen una influencia tanto directa como indirecta sobre el conjunto de actores económicos, situándose por tanto en el centro del escenario ${ }^{8}$. Por ejemplo, y según datos de la revista Fortune para 2014, solo las 500 empresas más grandes generaron 31.2 billones de ingresos, 1.7 billones en beneficios, emplean a más de 65 millones de personas y operan en 36 países.

Así, y como resultado de este proceso, las empresas transnacionales tienen un poder económico mayor que el de muchos estados. Por ejemplo, Wal-Mart, Shell y Exxon Mobil tienen unos ingresos anuales superiores al Producto Interior Bruto (PIB) de países como Austria, Sudáfrica y Venezuela. Telefónica y Repsol, por su parte, manejan unos volúmenes de ventas que duplican el PIB de Bolivia y el de Honduras, respectivamente. Y las ganancias de estas compañías, que se traducen cada año en grandes dividendos para sus principales accionistas y directivos, no han dejado de incrementarse tras el estallido financiero global de 2008. De esta manera, en 2013 la fortuna de los 25 mayores millonarios del mundo creció un 9\% respecto al ańo anterior (Hernández y Ramiro, 2015). Se trata por tanto de agentes imprescindibles para la consolidación y extensión del modelo económico global actual.

Tomando como base la hegemonía económica alcanzada en las últimas décadas, el poder corporativo se expande también al ámbito simbólico y cultural, con el objetivo de alcanzar el mayor consentimiento posible entre la población. De esta manera, las empresas transnacionales juegan un papel muy activo en la construcción de un relato que las legitime entre las mayorías sociales, accediendo y moldeando sus imaginarios por múltiples vías. En este sentido se emplean al máximo en desvincular sus actuaciones de las evidencias que las vinculan con graves impactos negativos de todo tipo, identificando estas como actuaciones aisladas y extraordinarias, incluso ajenas al centro corporativo, pero en ningún caso como patrones sistémicos vinculados con ciertos valores civiliza-

8 Esto no significa ni mucho que todas las unidades económicas estén sujetas a los mercados y cadenas globales, ya que existen múltiples experiencias que escapan a estas dinámicas actuales, tanto por decisión de construir fórmulas alternativas, como por la incapacidad de la globalización neoliberal de ocupar todos los espacios desde sus propias lógicas de maximización de la ganancia y de economía de mercado. No obstante, sí que tienen una muy fuerte influencia en dichas lógicas de mercado, hoy en día hegemónicas. 
torios hegemónicos. A su vez, y en sentido contrario, promueven - hasta el momento con cierto éxito- un relato que las identifica con valores positivos como el progreso, el desarrollo, el poder, el avance tecnológico y la generación de empleo (Ornelas, 2008). Dicho relato, además, se inscribe en la lógica de defensa de un imaginario hegemónico que limita las posibilidades de actuación global a los márgenes de la modernidad capitalista, y que promueve un modelo de sociedad coherente con el proyecto civilizatorio vigente, basado en una ciudadanía individualista, fragmentada, despolitizada y consumista (Fernández, 2015).

En este sentido las empresas transnacionales entienden el papel estratégico que tiene esta disputa cultural, por lo que invierten ingentes recursos en la misma, aprovechado su capacidad económica y los parámetros en los que se mueve actualmente la sociedad global. Así, la comunicación y la información también han pasado por el filtro de la mercantilización y la privatización, dando lugar a la conformación de mass media donde prima el ánimo de lucro, la ganancia y la acumulación sobre la veracidad y el rigor (Serrano, 2013). Además, las grandes corporaciones invierten grandes cantidades en marketing, responsabilidad social corporativa (RSC) y publicidad, en ese ánimo de hacer presente el poder corporativo en todas las facetas de la vida. Desarrollan en definitiva una estrategia que bombardea al planeta con el imaginario civilizatorio y el relato positivo sobre las grandes corporaciones, apelando y colonizando directa o indirectamente nuestras miradas y tratando de delimitar nuestros márgenes posibles de actuación (Chomsky y Herman, 2000).

En todo caso, el acumulado de poder económico y cultural no es suficiente, por lo que este debe sostenerse sobre una sólida base política acorde con la posición que ocupan actualmente las empresas transnacionales. En este sentido, estas han participado activamente en la reformulación de las ya de por sí cuestionadas acepciones vigentes de soberanía y ciudadanía — principios débiles de la modernidad capitalista, como ya indicamos en el apartado anterior-, jugando un rol fundamental en un momento de hegemonías políticas difusas y multipolares. El resultado de este complejo proceso es una agenda y una estructura política global basada en un enfoque de democracia de todavía de menor intensidad, que tensiona aún más la atribulada relación entre esta y el capitalismo, y que se escora en favor del poder corporativo.

Respecto a la agenda vigente, esta se caracteriza en primer lugar por el alejamiento ciudadano de la toma de decisiones, algunas de las cuales — precisamente las de cierta relevancia sistémica- dejan de definirse en el marco del estado-nación en favor de ámbitos supraestatales —en los que no hay sujeto que pudiera ejercer la soberanía-, por lo que se afianza la política de carácter delegativo con mayores carencias de control popular. Además, en segundo lugar, esta democracia devaluada tiende a privatizarse - o corporativizarse - a partir de la labor de lobby, figura fundamental para entender hoy la política y que 
afecta a todos los niveles competenciales - desde Naciones Unidas y las estructuras regionales como la Unión Europea, hasta el ámbito estatal y local—, y que básicamente está conformada por grupos de presión de las grandes empresas que influyen sobre los y las tomadoras de decisiones. Por poner solo un ejemplo, hay 15.000 lobistas en el parlamento europeo, y de ellos un 70\% son de empresas transnacionales que defienden el statu quo civilizatorio y que se arrogan un papel que debería jugar el conjunto de la ciudadanía (Hernández, González y Ramiro, 2012). Es más, en el extremo de esta dinámica, los lobbies llegan a tener capacidad de negociación directa y secreta con las estructuras supraestatales antes mencionadas, mientras que la ciudadanía y los representantes políticos son ajenos a dichas negociaciones, como ocurre en el caso del TTIP o del TISA, hitos estratégicos de la agenda hegemónica como hemos visto en el primer apartado (Fernández, 2015).

Finalmente, y en tercer lugar, hablamos también de una democracia corrompida sistémicamente, ya que necesita de la corrupción como argamasa que facilite la suma de intereses y poderes necesaria para mantenerla en los términos de escasa intensidad en la que se despliega. Se trata así de una corrupción que define al propio modelo y que se materializa en la forma de sobornos, puertas giratorias, evasión y elusión de impuestos, paraísos fiscales, desvíos de fondos, clientelismo, primas, especulación, cierre de empresas, etc. (Hernández y Ramiro, 2015). Todas estas fórmulas responden no solo a voluntades concretas sino a una lógica civilizatoria que prioriza el progreso, el capitalismo, el lucro, la acumulación de ganancia individual como premisas del bienestar. En este sentido, no hablamos solo de un modelo en el que hay corrupción, sino más bien de una forma de gobierno definida desde la corrupción, en el que colaboran corporaciones, estados y organismos multilaterales.

Figura 4

Estructura Política Global

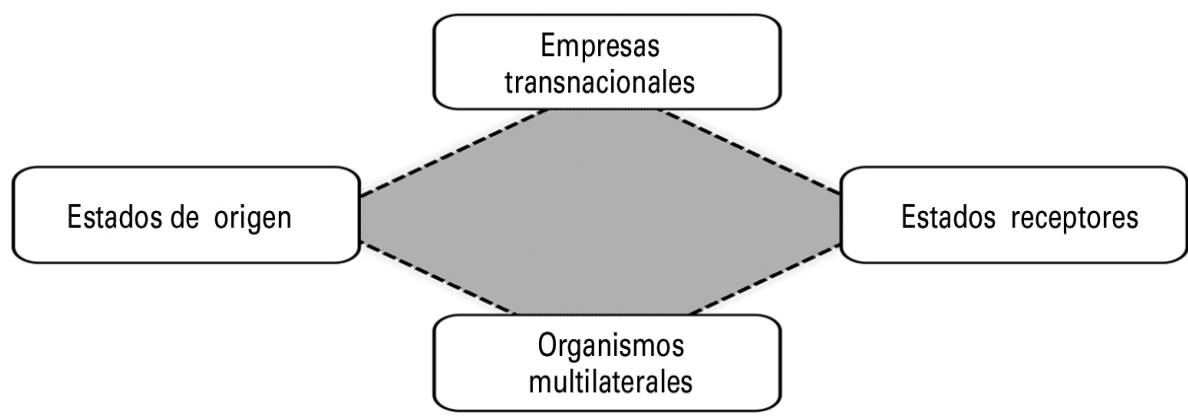

Fuente: Elaboración propia. 
Precisamente las grandes empresas han aprovechado esta agenda hegemónica de democracia de baja intensidad para incidir en la conformación de una estructura política global más favorable a sus intereses. Dicha estructura se podría representar como una figura de cuatro vértices en el que colaboran activamente las grandes instituciones multilaterales, los estados de origen de las empresas, los estados receptores de la inversión, y las propias empresas transnacionales — que se definen como el vértice fuerte del cuadrilátero político-. Por supuesto esta relación de colaboración no se da en todos los casos ni es natural per se, ya que hemos podido constatar casos de gobiernos que, desde posturas alternativas, han impulsado otras dinámicas que se enfrentan a la democracia de baja intensidad y a las empresas transnacionales. No obstante, la primacía del mantra civilizatorio y de la salida hegemónica a la crisis como horizonte, así como la práctica política de la agenda de democracia antes señalada, posibilitan en muchos casos esta estructura relacional que colabora en la expansión del poder corporativo: en primer lugar, los organismos multilaterales —influenciados por los lobbies - generan la normativa global y las estructuras de decisión favorables a las empresas; en segundo lugar, los estados de origen de las empresas transnacionales vinculan su destino a estas, apoyándolas desde el ámbito diplomático, con políticas de internacionalización, créditos blandos, incluso con apoyo militar si fuera necesario; en tercer lugar, los estados receptores compiten por la implantación de estas empresas mediante una carrera de desregulación de derechos a la baja acompańada por una fuerte dosis de corrupción, sin descartar el uso de la represión si fuera necesario (Hernández y Ramiro, 2015; Teitelbaum, 2010). Se trata, en definitiva, de una estructura que suma intereses en la búsqueda de una parte del pastel que ofrece el mantra civilizatorio, y en el que las empresas transnacionales juegan un papel crucial.

Son por tanto esta agenda y esta estructura política mundial las que sustentan el poder corporativo sobre una base firme, en la que este se sitúa en un lugar de primacía no solo sobre el poder popular, sino incluso de los agentes institucionales multilaterales, regionales, estatales y locales.

Por último, la fotografía final del poder corporativo se traslada del ámbito político al jurídico, cerrando el círculo a partir de una nueva legalidad global. De esta manera, las empresas transnacionales han conseguido imponer un nuevo Derecho Corporativo Global, una lex mercatoria que se sitúa por encima del marco internacional de los derechos humanos y de la propia capacidad de actuación política de los estados, dando lugar a una arquitectura de la impunidad en favor de sus intereses (Hernández y Ramiro, 2015; Teitelbaum, 2010). Así, la lex mercatoria está conformada por una muy diversa tipología de formatos, que van desde los más de 3.000 tratados y acuerdos globales, regionales y bilaterales vigentes sobre comercio e inversión, hasta los contratos que las instituciones establecen con las grandes corporaciones, pasando por los planes de ajuste estructural y los prestamos condicionados. 
Toda esta inflación normativa se basa, en primer lugar, en la defensa prioritaria y sin excepción de una serie de principios fundamentales: la seguridad jurídica de las inversiones como lógica inexcusable en favor de la salida hegemónica a la crisis, estableciendo el pacta sunt servanda - lo pactado se cumple - como máxima que paraliza todo intento de transformación en función de nuevas condiciones o de nuevas voluntades políticas; la armonización normativa a la baja en términos de derechos y libertades; el trato nacional para toda empresa extranjera, independientemente de las asimetrías de partida — considerando por tanto igual a los desiguales - así como de las pretensiones de desarrollar autónomamente políticas que cohesionen al territorio; el trato de nación más favorecida, ampliando las mejores condiciones ya existentes para los negocios en cualquier acuerdo a los nuevos que se pudieran firmar; la protección retroactiva de las inversiones; la no exigencia de desempeños tecnológicos, ecológicos, económicos y sociales a las grandes corporaciones y, finalmente, la imposición de fuertes compensaciones por posibles dańos generados - y por generar, en el caso de la apelación al lucro cesante-, que inhiban el enfrentamiento con las empresas transnacionales (Hernández y Ramiro, 2015). Estos son, en definitiva, los principios y valores fuertes del derecho internacional actual, la adaptación de los valores fuertes de la modernidad capitalista al momento actual.

Además, y en segundo lugar, el Derecho Corporativo Global impone estos principios sobre estructuras de arbitraje de los conflictos entre estados y corporaciones que escapan y/o se superponen al sistema público judicial. De esta manera, el Sistema de Solución de Diferencias de la Organización Mundial del Comercio (OMC), el Centro Internacional de Arreglo de Diferencias Relativas a Inversiones del Banco Mundial (CIADI), la Corte Internacional de La Haya, o la Corte Internacional de Arbitraje de la Cámara de Comercio Internacional (CCI), definen espacios de carácter privado para dirimir los conflictos, siendo las grandes empresas las únicas que pueden apelar a los mismos. Por lo tanto, no solo se igualan sujetos de derecho público con sujetos de derecho privado, sino que incluso se ofrecen mayores garantías a estos últimos, primando como decimos el ánimo de lucro sobre el interés general.

El resultado final de la primacía de estos principios y de estas estructuras de resolución de diferencias es una más que notable asimetría normativa, que blinda los derechos de las empresas transnacionales, a la vez que diluye sus obligaciones. En este sentido, la lex mercatoria supone un derecho fuerte, imperativo, coercitivo y ejecutivo, mientras que las obligaciones de las grandes empresas se reducen al cumplimiento de un derecho débil. Este se conforma en primer lugar por las legislaciones nacionales de los países receptores - en un contexto de desregulación neoliberal, y donde las responsabilidades no se amplían extraterritorialmente hacia el centro corporativo-; en segundo lugar por un marco internacional de los derechos humanos no exigible y que no es aplicable más que a los estados — por lo que las grandes empresas solo deben respetarlo—; y 
en tercer y último lugar, por el creciente papel internacional de la lógica voluntaria, unilateral y no vinculante de la RSC como preconizan el Pacto Global y los actualmente vigentes Principios Rectores sobre Empresas y Derechos Humanos de las Naciones Unidas (Ramiro, 2009).

Figura 5

Asimetría Normativa

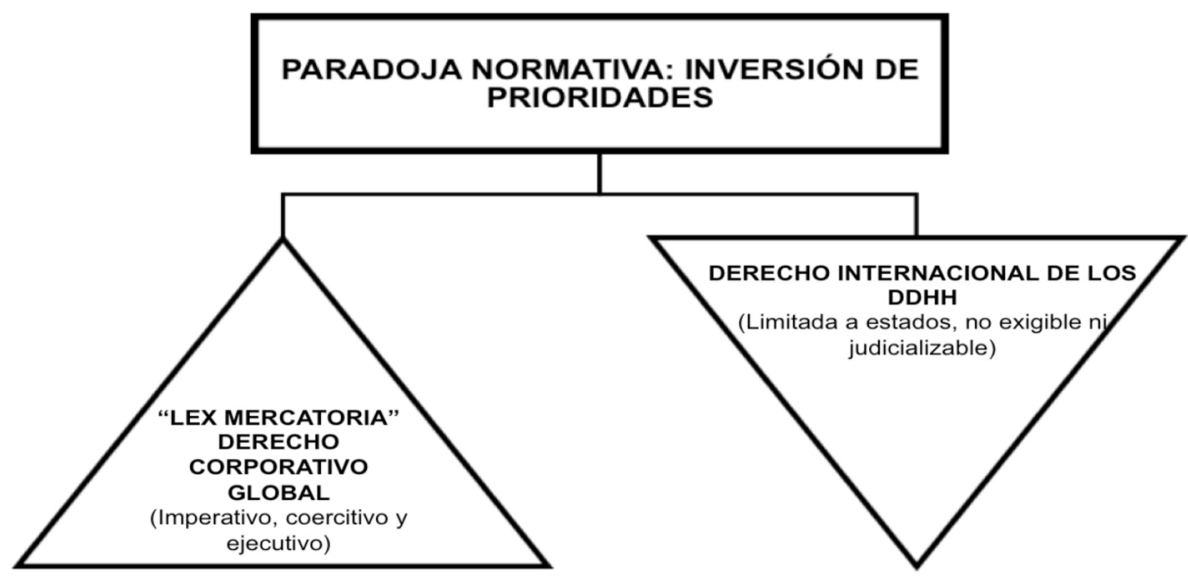

Fuente: Elaboración propia.

En definitiva, el poder de las grandes corporaciones se sustenta sobre una arquitectura de la impunidad perfectamente coherente tanto con la salida hegemónica de la crisis — que pretende eliminar toda traba a los negocios- como con los valores de la modernidad capitalista. De esta manera, la globalización neoliberal sigue profundizando sus claves identitarias y conforma un modelo de sociedad global que vincula la suerte del planeta con las lógicas de acumulación capitalista que abanderan las empresas transnacionales, frente a un contrapeso menguado de las instituciones públicas, que ven cercenadas sus capacidades políticas.

Este modelo genera toda una serie de impactos negativos - económicos, sociales, ecológicos, políticos, culturales - derivados de la actuación de las grandes corporaciones, y que han sido documentados en múltiples estudios ${ }^{9}$. Por su-

9 Entre ellas se encuentran, por ejemplo, las iniciativas de mapeo de los impactos sociales, ambientales y culturales de estas compañías que han puesto en marcha el Observatorio de la Deuda en la Globalización (ODG), FUHEM-Ecosocial y la Coordinación por los Derechos de los Pueblos Indígenas (CODPI); al igual que las investigaciones concretas sobre países, empresas y sectores económicos que han llevado a cabo, por seguir con plataformas y organizaciones del Estado espańol, 
puesto, no podemos afirmar que todas las empresas, en todos los sectores y en todos los territorios tengan un efecto pernicioso, y es necesario estudiar en cada caso específico su desempeño real. No obstante, y a pesar de ello, podemos identificar patrones de funcionamiento que en base a la competencia y a la primacía de la maximización de la ganancia, por un lado, y en función del poder corporativo acumulado en estas últimas décadas, por el otro, ofrecen un marco idóneo para el desarrollo de las claves identitarias de las empresas transnacionales, donde el bienestar general y la sostenibilidad del planeta ocupan un lugar menor, subordinado y residual. Esto da como resultado un vínculo fuerte entre grandes corporaciones y conculcación de los derechos humanos y de la naturaleza.

En definitiva, el análisis integral del poder corporativo resalta la caracterización de las empresas transnacionales como producto de la modernidad capitalista, así como su consideración como agente hegemónico en un contexto complejo e incierto, impulsando, defendiendo y vinculando su suerte a los parámetros del proyecto civilizatorio hegemónico. Son por tanto agentes fundamentales del conflicto capital-vida, situándose en términos generales en vanguardia de un modelo global que pone en riesgo la reproducción de la vida, por lo que es preciso generar alternativas que trasciendan tanto a dichos agentes como al modelo en el que operan.

\section{Alternativas en el conflicto capital-vida: bosquejo de marco teórico}

La crisis civilizatoria pone el foco de atención en el conflicto capital-vida, que a su vez nos conmina a generar propuestas alternativas a los valores y prácticas hegemónicas. No obstante, ¿cuáles son los horizontes emancipadores de dichas alternativas?, ¿hacia dónde dirigirlas?, ¿cuáles son las claves que marcan la idoneidad de unas alternativas y no de otras?

Estas preguntas de carácter teórico no solo no deben considerarse como asuntos menores en un contexto de urgencia por poner en práctica iniciativas concretas que enfrenten la multidimensionalidad y amplitud del poder corporativo, sino que al contrario cobran especial sentido. Así, no toda propuesta que se enfrente a la modernidad capitalista y a sus agentes hegemónicos tiene por qué ser necesariamente óptima ni generar un impacto positivo en defensa de la vida. En este sentido, tan importante como la práctica política de confrontación con los valores que generan el sistema de dominación múltiple, es también el debate sobre los horizontes teóricos desde los que plantear dicha disputa, los pilares so-

la Campaña Ropa Limpia, ¿Quién debe a Quién?, Ingeniería sin Fronteras, SETEM, Justicia i Pau, Ecologistas en Acción, Veterinarios sin Fronteras y el Observatorio de Multinacionales en América Latina (OMAL)-Paz con Dignidad, entre otras. 
bre los que sustentar las estrategias de emancipación. De esta manera, es preciso integrar la acción y la reflexión en un todo coherente que permita avanzar en el logro de espacios ajenos a la primacía del capital. Por lo tanto, el trabajo de reflexión teórica nacido de la práctica política, y la práctica política sistematizada que fortalece la reflexión teórica se convierten en elementos sustanciales e indivisibles de toda estrategia transformadora, confrontando los saberes de la dominación con los saberes de la emancipación, enfrentando la epistemología capitalista a otras epistemologías populares (Ornelas, 2008) que establezcan una forma alternativa de definir alternativas (Sousa y Meneses, 2014). Por lo tanto, no toda propuesta es válida desde la simple negación de los valores hegemónicos, ni es posible separar el debate teórico del político-práctico.

Las alternativas, en este sentido, deberían impulsarse desde una doble premisa que, por un lado, analice críticamente y se adapte dinámicamente al contexto mientras que, por el otro, sea capaz de avanzar en la construcción de relatos que disputen hegemonías desde otros parámetros, llegando de esta manera a las grandes mayorías sociales a partir de nuevas claves teóricas, políticas, discursivas y prácticas.

Respecto a la primera de las premisas, los dos pilares de nuestro diagnóstico global - la crisis civilizatoria y el conflicto capital-vida-, nos invitan a generar una agenda que enfrente de manera eficaz el sistema de dominación múltiple desde la articulación inclusiva e integral de enfoques complementarios, que coadyuven en la conformación de un sujeto de emancipación plural y diverso. Esta premisa — que no es garantía de ningún éxito ante una realidad incierta-, sí que nos permite al menos, y desde un permanente análisis crítico del complejo contexto mundial y local, enfrentar las estrategias de transformación desde claves más sólidas. Además, la segunda premisa antes señalada para la conformación de alternativas pone el acento no solo sobre la necesidad de generar nuevos contenidos, sino también en la implementación de fórmulas que permitan comunicar dichos contenidos para disputar imaginarios y relatos entre las mayorías sociales. En definitiva, es importante articular un discurso coordinativo - que aglutine a actores que, en base a claves compartidas, creen, deliberen, argumenten, negocien y lleguen a acuerdos alternativos - con un discurso comunicativo — que permita presentar, contestar, deliberar y legitimar dichos acuerdos- (Schmidt, 2011).

En este apartado nos centraremos en los parámetros que nos permitan avanzar en la construcción de dicho discurso coordinativo y comunicativo. Para ello planteamos la definición de un marco teórico para el impulso de alternativas emancipadoras desde un enfoque integral e inclusivo. Empezaremos, en este sentido, destacando en primer lugar algunas propuestas teóricas que, entre muchas otras, cumplen con estos requisitos a la vez que son referencia para $-y$ surgen de- múltiples prácticas políticas de resistencia a lo largo y ancho del 
mundo. En segundo lugar, trataremos de sintetizar los parámetros comunes de estas propuestas en una serie de puntos que nos permitan definir otras bases civilizatorias sobre las que incidir en el conflicto capital-vida, desde la defensa de esta última. Finalmente y en tercer lugar se establecerán, de manera tentativa, cuatro ideas-fuerza sostenidas sobre dichas bases civilizatorias, que sirvan como horizonte de emancipación para la definición de claves que enfrenten la modernidad capitalista y el poder corporativo ${ }^{10}$.

Comenzamos esta secuencia de referencias, bases, ideas-fuerza y claves por el primero de sus términos. Destacamos en este sentido, y desde una perspectiva inclusiva y popular, los intentos de complementación del feminismo, el ecologismo, el buen vivir y la economía solidaria ${ }^{11}$. Por supuesto es necesario reconocer desde la humildad la existencia de otras muchas referencias teóricas y políticas posibles, así como el camino que aún queda por recorrer en esta lógica de intersección. No obstante, se trata de un ejercicio incipiente pero necesario, en el que las propuestas que a continuación comentaremos nos pueden servir en todo caso como base sólida para dicho camino por construir, ya que representan miradas legitimadas desde un amplio abanico teórico y político, y que no solo diagnostican la realidad sino que proponen nuevas bases civilizatorias y nuevos horizontes de emancipación sobre los que sustentar el futuro.

De esta manera, ahondaremos en la propuesta ecofeminista (Orozco, 2014); la apuesta por articular ecología y justicia social (Riechmann, 2006); el intento de buscar los nexos entre buen vivir, economía feminista y economía solidaria (León, 2012 y 2014); y finalmente, un intento de posicionar algunas ideasfuerza derivadas de estos y otros enfoques (Fernández, Piris y Ramiro, 2013).

Comenzando con este somero análisis, Amaia P. Orozco (2014) apuesta por el decrecimiento feminista como referencia para las lógicas emancipadoras desta-

10 Separar el marco teórico y político de las alternativas a la modernidad capitalista del de las alternativas al poder corporativo supone un ejercicio complejo, en el cual las líneas divisorias no están perfectamente delimitadas. Como hemos dicho previamente, es importante generar alternativas al agente hegemónico del proyecto civilizatorio hegemónico, pero es prácticamente imposible plantearlas sin un horizonte de superación de dicho proyecto. Esta será una tensión permanente a lo largo de la construcción del marco teórico, a la cual trataremos de responder en mejores condiciones en el siguiente apartado, cuando analicemos el marco político y defendamos una lógica de transición en la construcción de alternativas.

${ }^{11}$ Aunque en el análisis que a continuación expondremos de complementación de enfoques no hacemos referencia explícita al pensamiento marxista, este artículo recoge toda una serie de elementos de interés derivados de la teoría y práctica marxista. Destacamos, en primer lugar, la relevancia del trabajo digno, desarrollado en autonomía e interdependencia, no explotado y no enajenado como eje de emancipación, así como del conflicto entre este y el capital. En segundo lugar, la apuesta por una sociedad igualitaria como horizonte. En tercer lugar, la lucha contra la propiedad privada de los medios de producción como premisa para alcanzar dicha igualdad. En cuarto lugar, la defensa de la democracia económica, también en el centro de trabajo y, en quinto lugar - y aunque esto es más discutible hoy todavía - el vínculo entre socialismo y ecología (Foster, 2004). 
cando, en primer lugar, la clave de la defensa de la sostenibilidad y cuidado de la vida. Este, según la autora, es un fenómeno finito, vulnerable e inseparable por tanto de los conceptos de ecodependencia, interdependencia y responsabilidad colectiva. En segundo lugar, destaca la necesidad de tener una mirada abierta sobre la economía y el trabajo, que integre también todos los espacios no mercantiles que inciden en la reproducción de la vida (personas, hogares, comunidad, ámbito público), replanteando el conjunto desde el papel central de la reproducción vital. De esta manera, se insiste específicamente en el impulso a dinámicas que hagan decrecer las esferas mercantiles de acumulación, que promuevan un menor consumo para vivir mejor, que democraticen los hogares y acaben con la división sexual del trabajo, y que primen el debate sobre los comunes y su gestión pública y/o comunitaria. Finalmente, y en tercer lugar, plantea dos principios fundamentales a la hora de pensar alternativas, como son la universalidad — validez generalizada - y la singularidad —adaptadas a las asimétricas situaciones y posiciones que cada quién ocupa-.

Por otro lado, Jorge Riechmann (2006) propone cinco claves que nos permitan avanzar hacia sociedades ecológicamente sostenibles y justas, rompiendo claramente con la lógica capitalista. Estos son la gestión global de la demanda, en defensa de un consumo menor y democráticamente planificado; la biomímesis, rediseñando nuestra tecnoesfera en coherencia con los flujos vitales de energía, materiales y residuos; la ecoeficiencia en el uso de materias primas y energía; la precaución frente a la fe en la tecnociencia y en su carácter neutro; y, finalmente, la igualdad social como premisa política inexcusable.

A su vez, Magdalena León (2012 y 2014) parte de la definición de buen vivir como logro colectivo de una vida plena o en plenitud, basada en relaciones armónicas y equilibradas entre los seres humanos y todos los seres vivos, en la reciprocidad y en la complementariedad. A partir de ahí, plantea los vínculos de este enfoque con la economía feminista y la solidaria, haciendo una apuesta por la sostenibilidad de la vida frente a la reproducción ampliada del capital, desde una fuerte crítica al individualismo, al progreso, al bienestar y al crecimiento. Bajo esta premisa propone, por un lado, el reconocimiento y fomento de la diversidad económica, destacando especialmente el papel central de la economía solidaria y de sus principios (enfoque normativo de la economía, relevancia del trabajo, tratamiento no capitalista del capital, democracia participativa), más allá de la consideración de esta como un aspecto social o como simple referencia filosófica. Por el otro, plantea el distanciamiento de una visión sectorial, cosmética e inercial del género en la economía, desde un enfoque inclusivo y abierto a todas las labores necesarias para la reproducción de la vida.

Finalmente, por nuestra parte (Fernández, Piris y Ramiro, 2013) proponemos seis ideas-fuerza como horizontes de emancipación para la construcción de 
alternativas, a partir de diferentes enfoques teóricos ${ }^{12}$ : la centralidad de la sostenibilidad de la vida, frente a la que se otorga actualmente a la reproducción ampliada del capital; el reconocimiento y articulación de la diversidad, frente a la pretendida universalidad del modelo hegemónico y a su jerarquización de seres, poderes y saberes; la democracia participativa, que se contrapone a la democracia de baja intensidad que ofrece la fórmula política liberal-representativa; la relevancia de lo colectivo y de la comunidad frente al individualismo; la politización de lo cotidiano dentro de dinámicas emancipadoras que unen lo general con lo personal; y la confrontación con la modernidad capitalista como premisa de urgencia ante el momento que vivimos.

Todas estas propuestas son, en definitiva, una serie de esfuerzos que contribuyen al debate estratégico sobre el marco de referencia para afrontar la construcción de alternativas a la modernidad capitalista y al poder corporativo. Así, y a pesar del camino todavía por recorrer en este sentido, nos permiten recoger algunos elementos comunes, nuevas bases civilizatorias y nuevas ideas-fuerza y claves emancipadoras sobre las que construir relatos contrahegemónicos y estrategias políticas de transformación, en disputa en favor de la vida y frente a la primacía del capital.

Y son precisamente tres elementos complementarios y consustanciales a nuestra caracterización de la vida ${ }^{13}$ los que nos van a servir para sinterizar el conjunto de bases civilizatorias surgidas de las diferentes reflexiones antes expuestas, pasando ya al segundo punto de la secuencia en la que se estructura este apartado. En este sentido planteamos dichas bases en función de la constatación de la vida, en primer lugar, como realidad ecodependiente, finita y vulnerable; en segundo lugar, la vida como fenómeno diverso; en tercer lugar, la vida como proceso interdependiente y que se desarrolla en comunidad.

La primera de las bases responde a la necesidad de actuar en consecuencia con la constatación de que vivimos en un espacio ecológicamente cerrado, y en el que por tanto existen límites físicos que no pueden ser superados en lo que se refiere al clima, a las fuentes de energía, a los materiales y a los residuos. En este sentido, no todo modelo de producción, consumo y organización social es viable

12 La economía ecológica (Naredo, 2006), la ecología política (Herrero, Cembranos y Pascual, 2011), el decrecimiento, la economía feminista para la sostenibilidad de la vida, la soberanía alimentaria, el Buen Vivir/Sumak Kawsay, el Vivir Bien/Sumak Kamaña (Acosta, 2010), la economía solidaria, las propuestas de descolonización, la democracia radical (Calle, 2011) o la plurinacionalidad de los estados.

13 La vida como síntesis de la humanidad y la naturaleza, no como un mero reflejo de las lógicas de la naturaleza, que pudieran operar en sentidos diferentes e incluso contradictorios. En este sentido, nos referimos a los elementos que guían a la vida para su autorreproducción ampliada en términos generales. 
Figura 6

Bases Civilizatorias Alternativas

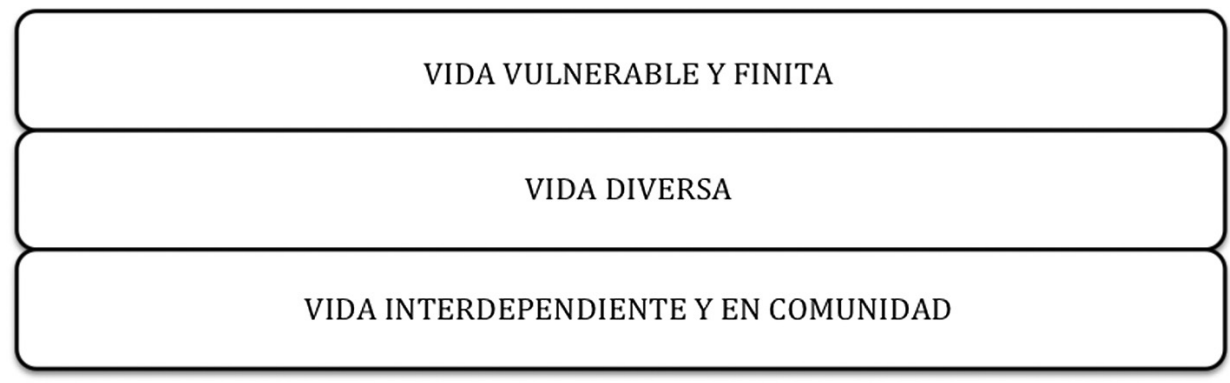

Fuente: Elaboración propia.

ni deseable, por lo que es preciso optar por aquéllos que mejor defiendan la reproducción de la vida y su cuidado —obviando la dicotomía entre humanidad y naturaleza-.

La segunda base pone el acento en la diversidad vital existente y en la necesidad de su sostenibilidad como valor prioritario. De esta máxima se extraen una serie de conclusiones significativas. Así, y desde el ámbito normativo, el reconocimiento de la diversidad de conceptualizaciones de bienestar y de justicia, así como el énfasis en la importancia de su coexistencia y articulación a partir de referentes compartidos en defensa de la vida. Desde el ámbito epistemológico, el impulso a las diferentes epistemologías y saberes populares más allá del científico, en una lógica de diálogo permanente y fluido entre los mismos (Sousa, 2006). Desde el ámbito político, la constatación de agendas y sujetos que parten de situaciones y posiciones asimétricas que deben superarse desde claves inclusivas, universales pero singulares, que transformen relaciones de poder y que eviten el trato igual a los y las desiguales. Finalmente y desde el ámbito ecológico, tal y como hemos indicado previamente, se destaca el esfuerzo por convertir a la vida en su conjunto como centro del análisis, desde una lógica de ampliación y reproducción de su diversidad.

Precisamente este reconocimiento y articulación de la diversidad está directamente vinculado al conflicto como elemento propio de todo proceso vital, dada la variedad normativa, epistemológica, política y ecológica que antes señalábamos. En este sentido, y dentro de una lógica general de conflicto entre el capital y la vida —en el que se pretende trascender valores, estructuras, agentes y dinámicas hegemónicas - es preciso también reconocer, explicitar y superar los diversos conflictos que subyacen en la propia reproducción de la vida, a partir de identidades, posiciones y situaciones diferentes. 
Por último, la tercera base civilizatoria insiste en que, frente a las pretensiones individualistas, la vida es un proceso que siempre se desarrolla en colectivo, por lo que es imposible evadir el concepto y la práctica comunitaria ${ }^{14}$. Se destaca de esta manera la necesidad de articular la reproducción de la vida diversa en base a procesos colectivos y democráticos, partiendo de las diferentes situaciones y posiciones que se ocupan en cada caso. De esta manera, la participación en todas aquellas decisiones fundamentales que afectan a nuestras vidas se torna en premisa, así como principios como la reciprocidad y complementariedad frente a la competencia como valor de la modernidad capitalista.

En definitiva, las tres bases civilizatorias alternativas que proponemos nos definen un marco de partida para cualquier modelo social, en el que este debe en primer lugar enfrentar la grave crisis ecológica desde la asunción de los límites del planeta; en segundo lugar, asumir e impulsar la diversidad de seres, poderes y saberes, actuando sobre el múltiple conflicto que se sitúa en el corazón de la disputa entre el capital y la vida; finalmente, y en tercer lugar, enfrentar dichos conflictos desde la defensa de lo colectivo, a partir de una apuesta decidida por el poder popular y la democracia participativa.

\section{Figura 7}

\section{Bases Civilizatorias e Ideas Fuerza Emancipadoras}
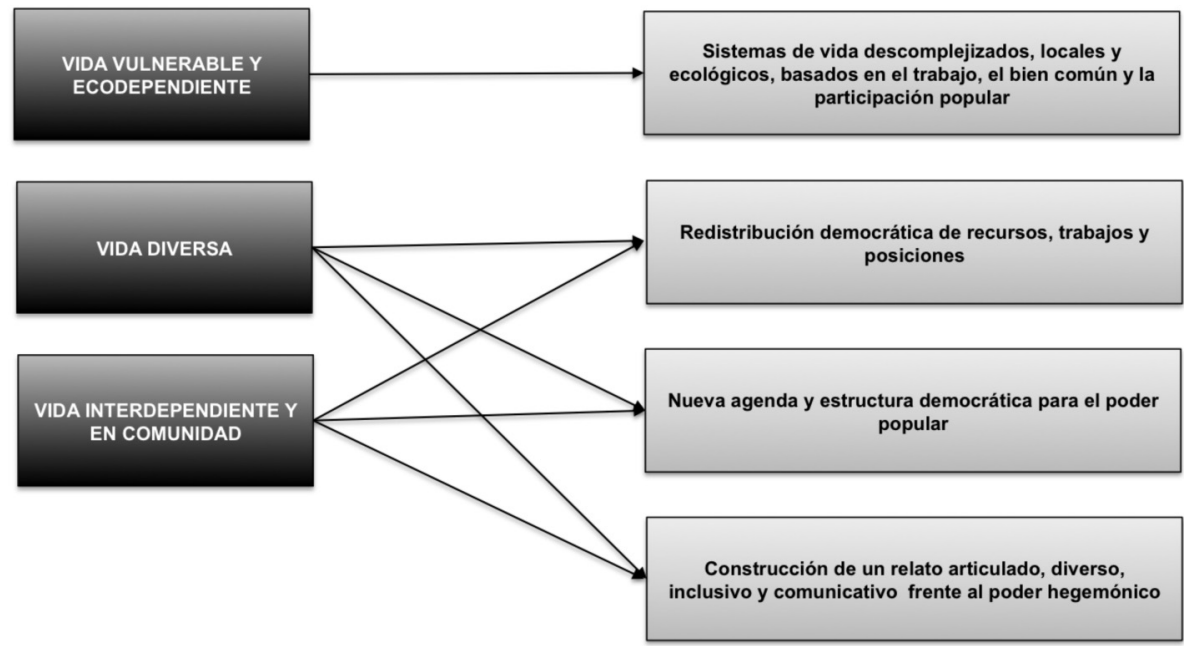

Fuente: Elaboración propia.

${ }^{14}$ Una práctica comunitaria que, por un lado, no se reduce al ámbito local sino que contiene a su vez lógicas globales. Además, por el otro, lleva implícita una tensión permanente con la autonomía personal. 
A partir de ahí, avanzamos en el siguiente punto de nuestra secuencia, proponiendo una serie de ideas-fuerza — y de claves vinculadas a las mismas - que prefiguren el horizonte de emancipación desde el que impulsar procesos alternativos que enfrenten el sistema de dominación múltiple y el poder corporativo. No se trata en este sentido de definir dogmas únicos o recetarios cerrados, sino de contar al menos con elementos que nos permitan prefigurar y/o delimitar por dónde creemos que es idóneo avanzar.

En primer lugar se apuesta por modelos de vida que, a partir de criterios ecológicos y democráticos derivados de la base de una vida vulnerable, diversa y colectiva, optan por lo local y por el territorio como espacio estratégico sobre el que sustentar la vida, sin menoscabo de la fundamental articulación local-global. De esta manera se proponen horizontes que tiendan a modelos descomplejizados en los que se vaya progresivamente desmercantilizando espacios sujetos a lógicas capitalistas en favor de fórmulas alternativas basadas en los principios de la economía solidaria. Además, se persiguen modelos basados en un consumo responsable - y menor en términos generales—, que a su vez priorice procesos de transición energética frente a la dependencia fósil.

En lo que se refiere a la segunda idea-fuerza emancipadora, y como elemento complementario a la propuesta de nuevos modelos socioeconómicos que subyace a la primera, se destaca la importancia de la redistribución igualitaria como prioridad. En este sentido, no es posible generar alternativas sin enfrentar las crecientes desigualdades actuales. Partiendo de esta premisa, y en función de las bases civilizatorias que propugnan una vida diversa y en colectivo, se plantea una lógica redistributiva que no se limita únicamente a los recursos - a través de políticas públicas o de transformaciones en la propiedad de los mismos-, sino que también se refiere a los trabajos. De esta manera, se amplía la mirada del modelo más allá del mercado y se pone la diana en la superación de la actual división sexual del trabajo, en una lógica de democratización de los hogares. Por último, también incluye una redistribución de posiciones geopolíticas y económicas en el tablero mundial, insistiendo por ejemplo en la necesidad de superar patrones de dependencia y especialización, como la matriz agrario-exportadora de muchos países del Sur Global.

Respecto a la tercera idea-fuerza emancipadora, esta sería el sustento político de las otras dos claves previas que prefiguran modelos socioeconómicos alternativos. En este sentido, hace referencia a la necesidad de dar forma a una nueva agenda y estructura política que ponga en valor el poder popular desde una democracia participativa y radical, y que por tanto supere a las actualmente hegemónicas, ya explicadas en el segundo apartado. Así, se apuesta por devolver al poder político la primacía sobre el económico desde la lógica de una ciudadanía crítica, organizada y participativa en su territorio, en los espacios regionales y en los globales, poniendo fin a las dinámicas de privatización y corrupción. 
Finalmente, la cuarta clave se vincula con la necesidad de construir un discurso comunicativo, un relato que pudiera alcanzar legitimidad entre las mayorías populares y abrir la senda de posibilidad que el horizonte de construcción de alternativas precisa. En este sentido, esta idea-fuerza llama por un lado a fortalecer los esfuerzos de denuncia de los riesgos que se asumen en el actual proyecto civilizatorio y de los impactos de sus agentes hegemónicos. Por el otro, incita a incidir en el imaginario colectivo sobre la necesidad y viabilidad de abrir y explorar nuevos caminos, desde lógicas de investigación, comunicación y educación alternativas y emancipadoras.

Figura 8

Claves de emancipación
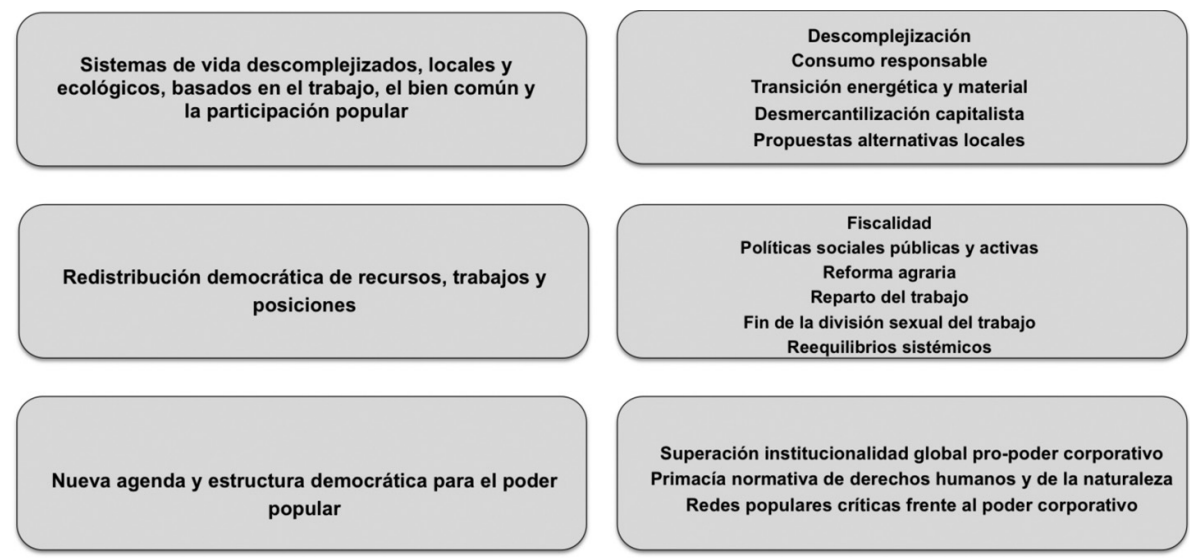

Construcción de un relato articulado, diverso e inclusivo frente al poder hegemónico

Investigación, comunicación e incidencia de impactos y alternativas al poder corporativo Educación emancipadora

Agenda política articulada, diversa e inclusiva frente a poder corporativo

Fuente: Elaboración propia.

En este punto concluimos nuestra secuencia y por tanto la definición de nuestro marco teórico de referencia. Este se basa inicialmente en un diagnóstico global centrado en el carácter civilizatorio de la crisis y en la primacía del conflicto capital-vida. Este último concepto nos urge a la construcción de un discurso coordinativo y comunicativo que permita impulsar alternativas a la modernidad capitalista y al poder corporativo. Y para ello nos sostenemos sobre bases civilizatorias que parten de la naturaleza vulnerable, diversa y comunitaria de la vida para ofrecernos una serie de ideas-fuerza y claves emancipadoras sobre las que sustentar procesos alternativos. Estas apuestan específicamente 
por modelos socioeconómicos basados en el territorio, en el trabajo y en la superación de la urgencia ecológica; por establecer la igualdad como valor a partir de la redistribución de recursos, trabajos y posiciones; por la defensa de lo colectivo y la democracia participativa frente al poder económico; y por asumir no solo el reto de plantear contenidos alternativos, sino también de fórmulas de comunicación que lleguen a las mayorías sociales.

Es este bosquejo de marco teórico el que, junto al marco político que analizaremos en el siguiente apartado, nos debe permitir contar con ciertos elementos para imaginar, pensar, planificar, implementar, evaluar y sistematizar procesos e iniciativas alternativas.

\section{Alternativas al poder corporativo: bosquejo de marco político}

Si el marco teórico nos puede servir para definir las sendas sobre las que transitar en el conflicto capital-vida, es necesario complementar este con una serie de elementos de carácter político que permitan «aterrizar» las ideas-fuerza y las claves emancipadoras en estrategias concretas de disputa con el poder corporativo. En este sentido, el bosquejo de marco de referencia que propone este artículo se nutre tanto de elementos teóricos como políticos.

Precisamente esta tensión entre teoría y política no se resuelve fácilmente, ya que el aterrizaje a la práctica de los elementos más abstractos está atravesado por múltiples nudos de complejidad, que descansan tanto sobre las más diversas asimetrías de partida a la hora de definir e impulsar estrategias concretas, como en la incertidumbre y la linealidad que acompańa a todo proceso político. En este

Figura 9

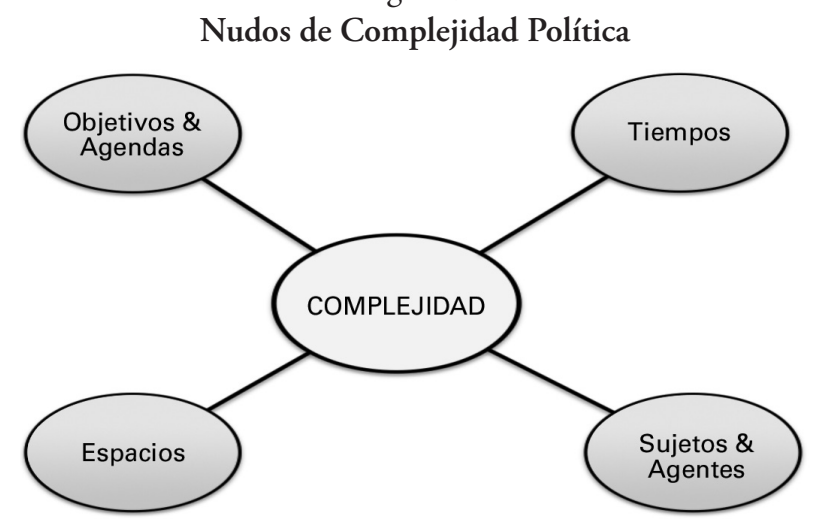

Fuente: Elaboración propia. 
sentido, destacamos cuatro nudos de complejidad de especial relevancia, vinculados en primer lugar a los objetivos y agendas perseguidos, y en segundo, tercer y cuarto lugar a los tiempos, a los espacios y a los agentes de la emancipación, respectivamente.

Respecto al primer de los nudos, se constata la especial complejidad de avanzar en las ideas-fuerza propuestas en base a agendas amplias, diversas e inclusivas. Así, el énfasis en cómo garantizar el equilibrio y la intersección de dimensiones complementarias, o el debate abierto sobre cómo organizar lo colectivo en base a lógicas públicas, comunitarias, sociales y/o privadas —incluso la viabilidad de la existencia de empresas transnacionales en un horizonte alternativo- plantean importantes retos que complican la generación de un discurso coordinativo. A esto se le suma, además, lo complejo de convertir estas agendas en un relato que logre acceder a los imaginarios de las mayorías sociales.

Pasando al segundo nudo — vinculado al tiempo de la emancipación-, es importante destacar que se parte hoy en día de una asimetría muy notable en favor del poder corporativo, además de que el hecho de avanzar en los horizontes emancipadores requiere de procesos largos y progresivos, en los que se van priorizando metas en función de la situación. Por lo tanto se precisa de procesos que vinculen el corto y el largo plazo en lógicas comunes, evitando de esta manera tanto la respuesta reactiva e inmediata, por un lado, como el empecinamiento en la implementación inmediata y absoluta de las claves emancipadoras, por el otro, como enfoques estratégicos principales. Además, y en una lógica progresiva, no se puede obviar la tensión entre alternativas a la modernidad capitalista y alternativas al poder corporativo que, estando muy relacionadas, plantean una dosis mayor de complejidad en las estrategias, incidiendo así tanto sobre el agente específico como en el sistema en el que se sustenta.

En lo que se refiere al tercer nudo —espacio de la emancipación-, partimos de la apuesta realizada por priorizar la lógica territorial como ámbito de desarrollo de los modelos alternativos de vida. Este énfasis se establece sin menoscabo a que el territorio se vincule globalmente para enfrentar por un lado la lógica sistémica y mundial de la modernidad capitalista, y que permita por el otro avanzar en una gobernanza a nivel planetario en el que convivan diversos referentes de bienestar y justicia. No obstante, este enfoque muestra la dificultad de compatibilizar los diferentes niveles de articulación estratégica para poder vincular lo local, lo estatal, lo regional y lo global.

Finalmente, el cuarto nudo de complejidad se refiere a quién o quiénes son los agentes de emancipación, planteándose fundamentalmente la tensa relación entre lógicas institucionales, por un lado, y lógicas sociales y comunitarias, por el otro, ya que parten de naturalezas y voluntades políticas diversas. Así, las instituciones públicas parten en primer lugar de las limitaciones ya comentadas a lo largo del artículo respecto al poder corporativo - no hay que confun- 
dir por tanto poder con gobierno-- en segundo lugar de una naturaleza basada en tiempos cortos electorales y presupuestarios, que la acercan más a lógicas redistributivas que de carácter profundo, así como en tercer lugar de una realidad de ser espacios en disputa en el que coexisten agendas y poderes diversos y frágiles. No obstante, pudieran desde sus políticas públicas tanto generar efectos palanca sobre procesos emancipadores y sobre sus agentes sociales, como también en sentido contrario cercenar, desvirtuar e incluso criminalizar los mismos. Por su lado, los movimientos sociales y comunitarios parten de una posición todavía más asimétrica respecto al poder corporativo, aunque de una naturaleza no tan apegada siempre al corto plazo, por lo que suelen abanderar propuestas emancipadoras con una profundidad y con una perspectiva temporal de mayor calado. A pesar de ello, pudieran existir «techos de cristal» a la implementación de sus procesos si no cuentan con el efecto "palanca» de las políticas públicas, e incluso pudieran caer, en el extremo, en cierto purismo respecto a la agenda, desdeñando el desafío de la política y el carácter procesual y de disputa de poder implícita a la misma.

En definitiva, estas cuatro tipologías de nudos de complejidad nos plantean una serie de preguntas para las que no se trata tanto de tener una respuesta cerrada y definitiva como de al menos definir apuestas específicas que complementen nuestro marco de referencia a modo de tendencias positivas. De esta manera se plantea, en primer lugar, la necesidad de priorizar aquellas alternativas que se formulen e implementen desde lógicas inclusivas de enfrentar el Sistema de Dominación Múltiple, y que planteen maneras creativas de enfrentar el debate sobre lo colectivo. En segundo lugar, se prima el análisis de las alternativas desde una lógica de transición en base a procesos graduales que vinculen lo urgente y lo necesario, lo inmediato y el horizonte último, y que por tanto impulse resistencias que se conviertan progresivamente en alternativas (Ramiro, 2015). En este sentido, y en las primeras etapas de ese proceso de transición, es importante disputar espacios al poder corporativo, poner «diques» a su enorme poder actual, pero sin abandonar el abordaje de la apuesta alternativa civilizatoria y sistémica. En tercer lugar, y en base a la defensa del territorio, se enfatiza la necesidad de alternativas que lo vinculen globalmente, dentro de lógicas cosmopolitas pero arraigadas (Tarrow, 2011). Y por último y cuarto lugar, se plantea como prioridad las alternativas que generan poder popular sólido, ciudadanía crítica, articulada y organizada, tanto si estas iniciativas parten de gobiernos como de movimientos y comunidades, pero en clave de corresponsabilidad (Gómez, 2016).

Por lo tanto, añadimos a nuestro marco teórico estos cuatro elementos políticos: apuesta por agendas inclusivas y creativas; por procesos graduales de transición; por la articulación global de los territorios; y por el fortalecimiento del poder popular desde la corresponsabilidad. Por supuesto, no se trata de premisas ni de precondiciones, sino más bien de referencias positivas que complementan 
las ideas-fuerza y las claves emancipadoras antes señaladas, asumiendo de esta manera la lógica de horizontes en un mundo complejo e incierto.

\section{Alternativas al poder corporativo: marco de referencia y conclusiones}

Concluimos el presente artículo recogiendo los diferentes elementos que nos han servido como base para la conformación del bosquejo de marco de referencia. No obstante, y antes de entrar en su lógica interna, es importante rescatar tres premisas sobre los que este se ha sustentado. En primer lugar, este bosquejo no pretende ser más que un insumo al abierto y dinámico debate sobre las alternativas al poder corporativo y al sistema vigente, planteando desde la humildad algunas claves que pudieran ayudar a vislumbrar otras sendas por las que transitar, y siempre desde el análisis inclusivo de lo que ya se impulsa, se piensa y se imagina desde lógicas contrahegemónicas. En segundo lugar, este ejercicio nace desde la urgencia por ahondar en estos debates, dado que vivimos un momento de riesgo planetario que, a su vez, nos ofrece una ventana de oportunidad, ya que los parámetros civilizatorios sufren un creciente cuestionamiento. Así, el cambio sistémico se está produciendo, pero se abren posibilidades para saber qué agendas y qué sujetos lo liderarán. Por último, y en tercer lugar, este marco se plantea desde la indivisibilidad entre los análisis teóricos y políticos, que deben alimentarse mutuamente desde un análisis crítico y permanente de la realidad.

Partiendo de estas premisas, comenzamos con nuestra síntesis del artículo recordando que caracterizábamos la crisis actual como un fenómeno civilizatorio, cuya génesis se sitúa en una serie de valores hegemónicos del proyecto de la modernidad capitalista (el progreso, el individualismo, la ciencia como saber único, la dominación de la naturaleza por el ser humano, la acumulación capitalista y la democracia liberal-representativa). Estos valores habrían definido una agenda y una estructura económica, política, cultural y social que nos ha conducido al atolladero histórico actual. Este no solo se manifiesta en crecientes desigualdades y en un modelo de gobernanza en el que el poder corporativo se impone al político, sino que incluso llega a ponerse en riesgo la propia reproducción de la vida misma, tal y como ponen de manifiesto la crisis climática y energética. Asistimos por tanto a la necesidad y a la urgencia por trascender los valores civilizatorios en base a otros alternativos, destacando el conflicto entre el capital —como metáfora de la modernidad capitalista — y la vida como eje estratégico de disputa.

A partir de este diagnóstico global basado en los conceptos de crisis civilizatoria y conflicto capital-vida, y en un contexto complejo e incierto, se plantea la necesidad de definir un marco de referencia teórico-político que nos permita vislumbrar, analizar, evaluar e implementar alternativas al poder corporativo y al 
sistema en el que este se sustenta e impulsa. Se enfatiza así la necesidad de combinar un discurso coordinativo que permita articular a agendas y sujetos diversos, con un discurso comunicativo que apele a los imaginarios de las mayorías sociales.

En función por tanto de esta doble lógica coordinativa y comunicativa, y a partir de diversas propuestas de definición de agendas inclusivas, se definieron unas bases civilizatorias alternativas en defensa de la reproducción ampliada de la vida, que nacían de la caracterización de esta como un fenómeno vulnerable, diverso y colectivo.

Precisamente de estas bases se establecieron tentativamente una serie de ideas-fuerza y claves que pudieran marcar la senda de otros horizontes alternativos. Estas proponen fundamentalmente apostar por el territorio como espacio estratégico de emancipación; la defensa de modelos socioeconómicos descomplejizados, desmercantilizados y basados en el bien común y el trabajo; la igualdad en la diversidad como principio guía para la redistribución de recursos, trabajos y posiciones; la democracia y el poder popular como premisa de organización política; y, por último, la insistencia en la construcción de relatos contrahegemónicos que a través de la comunicación y la educación emancipadora pudieran disputar espacios en el imaginario de las mayorías sociales, insistiendo en la viabilidad y necesidad del cambio desde las nuevas bases civilizatorias.

Además de estas claves teóricas, y dentro de la lógica indisoluble entre reflexión y acción, el bosquejo de marco de referencia se nutre también de una serie de reflexiones surgidas de la compleja práctica política. En este sentido, las ideas-fuerza y claves antes señaladas deberían aterrizarse sobre nuevos elementos que definan tendencias para priorizar en primer lugar alternativas que se basen en agendas inclusivas y creativas, que por lo tanto coadyuven en la conformación del sujeto plural y diverso de emancipación. En segundo lugar, se plantea la necesidad de asumir la lógica de transición y de proceso como parte indispensable de toda estrategia, y que por lo tanto vincule lo inmediato con lo estructural en lógicas progresivas. En tercer lugar, la apuesta por el territorio no exime su necesaria articulación global, haciéndolo además desde el reconocimiento de la diversidad y de la relevancia de la democracia. Precisamente la democracia y el poder popular son, en cuarto lugar, elementos a tener en consideración como sostén fundamental de toda estrategia de transición, tratando desde ahí de complementar lógicas institucionales y sociales.

Esta sería en definitiva la propuesta de bosquejo de marco de referencia para las alternativas a la modernidad capitalista y al poder corporativo. Su fin no es únicamente el de reconocer y sintetizar todas las iniciativas y propuestas que caminan ya en ese sentido, como el Tratado de los Pueblos (Hernández, 2016), las campańas globales y locales de sensibilización y boicot, la toma de tierras, las auditorías ciudadanas de la deuda, las propuestas de políticas públicas frente 
Figura 10

Marco de referencia alternativas al Poder Corporativo

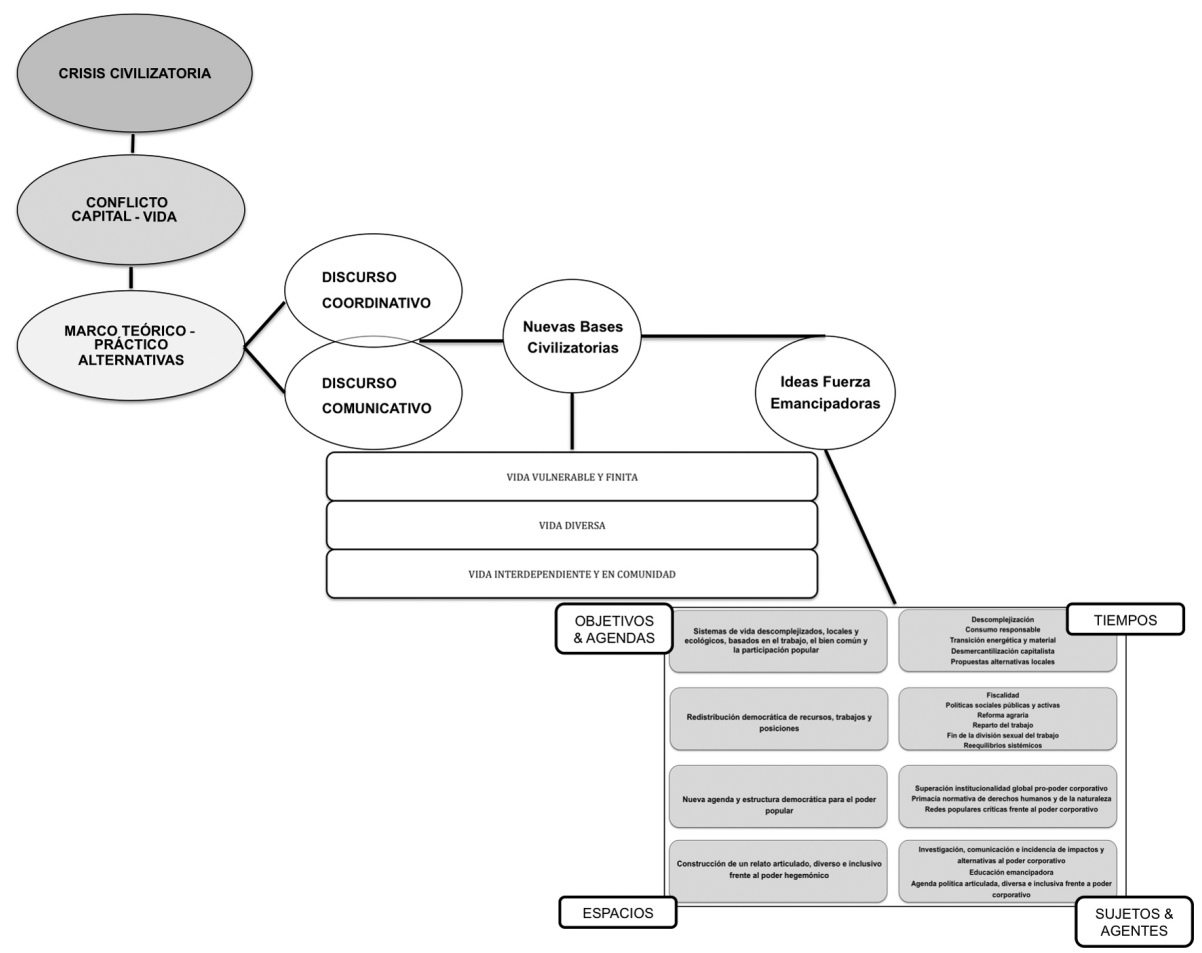

Fuente: Elaboración propia.

a la impunidad transnacional, los procesos sociales en favor de la soberanía alimentaria y la economía solidaria, etc. Es también el de, partiendo de lo que hay, tratar de imaginar quién, cómo y en qué podemos seguir insistiendo para que las mayorías sociales dirijamos el cambio que ya está viniendo, evitando así que una minoría lo haga. En esta línea, este artículo es parte de un proceso de investigación colectivo del Observatorio sobre Multinacionales en América Latina (OMAL), que continuará con los debates teóricos y políticos objeto de este artículo, pero que en una próxima publicación ampliará el marco de análisis hasta la profundización en ciertas iniciativas y procesos concretos que guardan coherencia con el marco propuesto, a la vez que destacan en su enfrentamiento al poder económico, simbólico, político y jurídico que hoy atesora el poder corporativo. 


\section{Bibliografía}

ACOSTA, Alberto (2010): «La indeseable pero inevitable crisis global», en BRAVO, Elizabeth (ed.), Estudios ecológicos n. ${ }^{\circ}$ 6: crisis financiera o crisis civilizatoria, Quito, Broederlijk Denle y Entrepueblos.

BANCO MUNDIAL (2010): Desarrollo y cambo climático. Informe de Desarrollo Mundial. BARTRA, Armando (2013), "Crisis civilizatoria» en ORNELAS, Raúl (coord.) (2013), Crisis civilizatoria y superación del capitalismo, México D.F., Universidad Nacional Autónoma de México (UNAM).

CHOMSKY, Noam y HERMAN, Edward (2000): Los guardianes de la libertad, Madrid, Crítica.

BERMEJO, Roberto, ARTO, Ińaki, HOYOS, David y GARMENDIA, Eneko (2010): Menos es más. Del desarrollo sostenible al decrecimiento sostenible, Bilbao, Hegoa. En: http://www.ehu.eus/ojs/index.php/hegoa/article/view/10593

CECENA, Ana Esther (2008): Derivas del mundo en el que caben todos los mundos, México D.F, CLACSO, Siglo XXI.

DESA (2010): Estudio Económico y Social Mundial 201.‥ En: http://www.un.org/es/mdg/ summit2010/pdf/overview_sp.pdf

DUBOIS, Alfonso (2014): Marco teórico y metodológico del desarrollo humano local, Bilbao, Hegoa. En: http://publicaciones.hegoa.ehu.es/assets/pdfs/307/Marco_Teorico_DHL. pdf? 1405078824

DUBOIS, Alfonso (2016): «Procesos colectivos y pensamiento alternativo en un escenario de cambio", en FERNÁNDEZ, Gonzalo y RAMIRO, Pedro (eds.): Propuestas y alternativas frente al poder de las empresas transnacionales, Revista Lan Harremanak n. ${ }^{\circ} 33$, Bilbao, UPV/EHU.

ECHEVERRIA, Bolívar (2010): "Crisis civilizatoria», en BRAVO, Elizabeth (ed.), Estudios ecológicos n. ${ }^{\circ}$ 6: crisis financiera o crisis civilizatoria, Quito, Broederlijk Denle y Entrepueblos, 3-11.

FEDERICI, Silvia (2014): El calibán y la bruja, mujeres, cuerpos y acumulación originaria, Madrid, Traficantes de Sueños.

FERNÁNDEZ, Gonzalo, PIRIS, Silvia y RAMIRO, Pedro (2013): Cooperación internacional y movimientos sociales emancipadores. Bases para un encuentro necesario, Bilbao, Hegoa.

FERNÂNDEZ, Gonzalo (2014): «Parámetros alternativos para una economía emancipadora», Economistas Sin Fronteras, Dossier n. ${ }^{0} 13$, 6-11. En: http://www.ecosfron.org/ wp-content/uploads/Dossier13.pdf

FERNÁNDEZ, Gonzalo (2015): "Alternativas para disputar el poder, el ser y el saber a las transnacionales», Revista Pueblos, 66, tercer trimestre, 28-31. En: http://www. revistapueblos.org/?p=19678

FERNÁNDEZ DURÁN, Ramón y GONZÁLEZ, Luis (2014): En la espiral de la energía, Madrid, Libros en acción/Baladre.

FONTANA, Josep (2011): Por el bien del imperio. Una historia del mundo desde 1945, Barcelona, Pasado y Presente.

GIDDENS, Anthony (1990): Consecuencias de la modernidad, Madrid, Alianza Editorial.

GÓMEZ, Laura (2016): «Sobre las instituciones públicas como instrumentos feministas emancipadores para un mundo en transición», en FERNÁNDEZ, Gonzalo y RA- 
MIRO, Pedro (eds.): Propuestas y alternativas frente al poder de las empresas transnacionales, Revista Lan Harremanak n. ${ }^{\circ} 33$, Bilbao, UPV/EHU.

HARVEY, David (2012): El enigma del capital y la crisis del capitalismo, Madrid, Akal.

HERNÁNDEZ, Juan; GONZÁLEZ, Erika y RAMIRO, Pedro (eds.) (2012): Diccionario critico de empresas transnacionales. Claves para enfrentar el poder de las grandes corporaciones, Barcelona, Icaria.

HERNÁNDEZ, Juan y RAMIRO, Pedro (2015): Contra la lex mercatoria, propuestas y alternativas para desmantelar el poder de las empresas transnacionales, Madrid, Icaria.

HERNÁNDEZ, Juan (2016): «El Tratado Internacional de los Pueblos para el control de las empresas transnacionales», en FERNÁNDEZ, Gonzalo y RAMIRO, Pedro (eds.), Propuestas y alternativas frente al poder de las empresas transnacionales, Revista Lan Harremanak n. ${ }^{\circ} 33$, Bilbao, UPV/EHU.

HERRERO, Yayo y GONZÁLEZ, Luis (2011): «Decrecimiento justo o barbarie», Revista Pueblos, 49, especial diciembre, 12-14.

LEÓN, Magdalena (2012): Redefiniciones económicas hacia el buen vivir: un acercamiento feminista, Quito, FEDAEPS-Fundación de Estudios, Acción y Participación Social. En: http://www.fedaeps.org/spip.php?article486

LEÓN, Magdalena (2014): «Economía solidaria y buen vivir: nuevos enfoques para una nueva economía», en REAS EUSKADI Sostenibilidad de la vida, aportaciones desde la Economía Solidaria, Feminista y Ecológica, Bilbao, REAS EUSKADI.

NACIONES UNIDAS (2013): Un nuevo Partenariado global: erradicar la pobreza y transformar las economias hacia el desarrollo sostenible, del Panel de Alto Nivel de Personas Eminentes en torno a la Agenda Global de Desarrollo Post-2015, Naciones Unidas.

NAREDO, José Manuel (2006): Raíces económicas del deterioro ecológico y social. Más allá de los dogmas, Madrid, Siglo XXI.

ORNELAS, Raúl (2008): «Saberes de la dominación: panorama de las empresas transnacionales en América Latina» en CECEÑA, Ana Esther (eds.), Saberes de la dominación $y$ de la emancipación, Buenos Aires, CLACSO.

OROZCO, Amaia (2014): Subversión feminista de la economía, aportes para un debate sobre el conflicto capital-vida, Madrid, Traficantes de Sueños.

PNUD (2008): La lucha contra el cambio climático: solidaridad frente a un mundo dividido. Informe de Desarrollo Humano.

RAMIRO, Pedro (2009): «Las multinacionales y la Responsabilidad Social Corporativa: de la ética a la rentabilidad", en HERNÁNDEZ, Juan y RAMIRO, Pedro, (eds.), El negocio de la responsabilidad, Barcelona, Icaria, 47-78.

RAMIRO, Pedro (2015): «Propuestas de transición a economías y sociedades post-capitalistas: de resistencias, regulaciones y alternativas», Revista Pueblos, 66, tercer trimestre, 32-34. En: http://www.revistapueblos.org/?p=19684

RIECHMANN, Jorge (2005): “¿Cómo cambiar hacia sociedades sostenibles? Reflexiones sobre biomímesis y autolimitación», Isegoría, 32, 95-118 En: http://isegoria.revistas. csic.es/index.php/isegoria/article/view/459/459

SCHMIDT, Vivien (2011): "A Discursive institutionalism: scope, dynamics, and philosophical underpinnings", en FISCHER, Frank and FORESTER, John (eds.), The Argumentative Turn Revised: Public Policy as Communicative Practice, Durham, NC, Duke University Press.

SERRANO, Pascual (2013): Desinformación, de cómo los medios ocultan el mundo, Madrid, Península. 
SOUSA, Boaventura de (2006): Renovar la teoría critica y reinventar la emancipación social, Buenos Aires, CLACSO.

SOUSA, Boaventura de y MENESES, María Paula (2014): Epistemologías del Sur, Madrid, Akal.

TARROW, Sidney (2011): Nuevo activismo transnacional, Madrid, Editorial Hacer.

TEITELBAUM, Alejandro (2010): La armadura del capitalismo, el poder de las sociedades transnacionales en el mundo contemporáneo, Madrid, Icaria Editorial.

VALDÉS, Gilberto (2009): Posneoliberalismo y movimientos antisistémicos, La Habana, Editorial de Ciencias Sociales.

VEGA, Renán (2009): «Crisis civilizatoria», Revista Herramienta, 42, octubre. En: http:// www.herramienta.com.ar/revista-herramienta-n-42/crisis-civilizatoria

WILKINSON, Carlos (2009): «La crisis civilizatoria», Proyecto Nacional. En: http:// proyectonacional.wordpress.com/2009/04/22/la-crisis-civilizatoria-por-carloswilkinson/

ZABALO, Patxi (2014): «La asociación trasatlántica de comercio e inversión en su contexto", Boletín de Recursos de Información de Hegoa, 41. 